\title{
Improvement of Heavy Oil Recovery by Nonionic Surfactant/Alcohol Flooding in Light of the Alkane Carbon Number and Interfacial Tension Properties
}

Ahmad Mohamed Alsabagh, Amany A. Aboulrous,* Mohamed Mahmoud Abdelhamid, Tahany Mahmoud, Amin Sharifi Haddad,* and Roozbeh Rafati

Cite This: ACS Omega 2021, 6, 18668-18683

Read Online

ACCESS | Lلll Metrics \& More | 回 Article Recommendations | st supporting Information

ABSTRACT: In this work, we prepared nonionic surfactants from waste cooking oil materials. Hydrolysis was carried out for palm and palm kernel waste cooking oils to get a mixture of free fatty acids. The mixture of free acids was esterified with sorbitan and then ethoxylated at different ethylene oxide units. Two surfactants exhibited promising surface-active properties among the six prepared surfactants based on the results of surface tension. The interfacial tension (IFT) around the critical micelle concentration was measured against a series of $n$-hydrocarbon to detect the minimum alkane carbon number $(\mathrm{ACN})\left(\Pi_{\min }\right)$ for each of these surfactants. The effect of normal and branched alcohols on $\Pi_{\text {min }}$ was also studied to design the surfactant/alcohol mixture for the chemical flooding process. From the results of IFT, the ethoxylated ester derivatives of palm kernel fatty acids

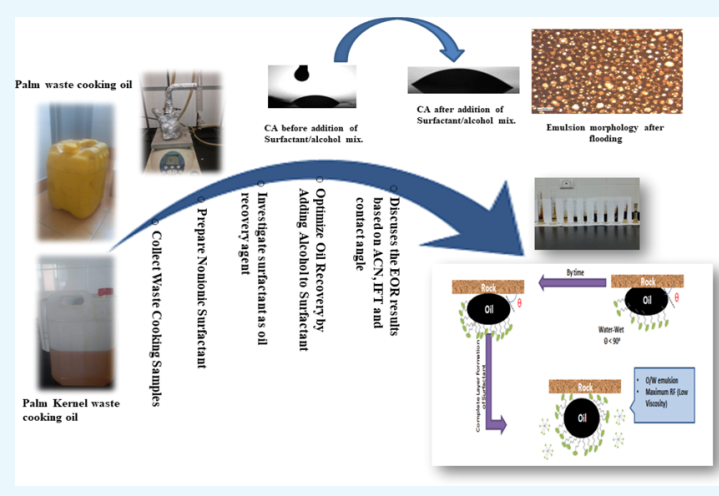
(EPK-20) exhibited minimum IFT $\gamma_{\min }\left(0.06 \mathrm{mN} \mathrm{m}^{-1}\right)$ at $\Pi_{\min }$ equal to 12 , and the ethoxylated ester derivatives of palm fatty acids (EP-40) achieved $\gamma_{\min }$ equal to $0.09 \mathrm{mN} \mathrm{m}^{-1}$ at $\Pi_{\min }$ of 10 . Branched alcohols shifted $\Pi_{\min }$ to a higher value to reach the equivalent ACN of the crude oil and decrease the IFT to lower values. The flooding process showed that the maximum oil recovery was obtained by EPK-20 (54.2\% when used purely and $66.2 \%$ when used with isoamyl alcohol). In comparison, EP-40 exhibited that oil recovery equals $46 \%$ without alcohol and $46.4 \%$ with iso-butanol alcohol. The results were interpreted and discussed based on interfacial properties, wettability alteration, and the ACN.

\section{INTRODUCTION}

The oil and gas industry has recently moved toward net-zero and more environmentally friendly techniques to produce oil from subsurface reservoirs. ${ }^{1}$ The typical oil production from any field involves three distinct processing stages: the primary recovery process, the secondary recovery process, and tertiary recovery or enhanced oil recovery (EOR). The key mechanism of the primary oil recovery process is the natural energy through the reservoir pores, but the maximum oil recovery from natural energy is up to \% 25. A little improvement in oil recovery can be achieved using the secondary recovery process, such as water and gas flooding, but this leaves more than $50 \%$ of the original oil in place within the rock space of the reservoir In the case of the EOR process, chemical and thermal flooding need to be used to boost the oil recovery further. ${ }^{2-8}$

The primary mechanism in the EOR process is pushing the residual oil out of the reservoir rock pores by physiochemical alterations of rock and fluid. ${ }^{1,9-16}$ Chemical flooding demonstrated good oil recovery results at the laboratory and field scale ${ }^{10-14}$ established by injecting chemicals (e.g., amphiphile, alkaline, and polymer) to displace the remaining oil within the reservoir rock after secondary recovery. Amphiphiles are substances that have both hydrophobic and hydrophilic species in their molecular structure. Examples of amphiphiles are surfactants and cosurfactants.

Surfactant flooding enhances the oil recovery by decreasing the interfacial tension (IFT) of the water-oil system and altering the wettability of the reservoir rock. Reduction in the IFT leads to a reduction in the capillary pressure and enhancement of the water injection sweep efficiency. ${ }^{17}$ Surfactant flooding is widely employed in EOR processes to manipulate petroleum reservoir fluid phase behavior to counteract the high capillary forces trapping oil in the pore spaces. ${ }^{5}$ The surfactants promote the formation of microemulsions at the oil-brine system interface, leading to a

Received: March 14, 2021

Accepted: June 24, 2021

Published: July 12, 2021 
significant reduction of the IFT of fluids present in the reservoir. It is required to efficiently mobilize a substantial percentage of the residual oil through wettability alteration and reduction in capillary forces. ${ }^{6}$ The main problem that challenges the efficiency of the surfactant flooding process is the loss of surfactants within the reservoir pores (rock surface adsorption), ${ }^{8}$ along with surfactant partitioning into the oil interface.

In past studies, the oil mobilization mechanisms from the pore spaces of the rock when surfactants were used have been explored. Chen et al. ${ }^{18}$ investigated different cationic surfactants (Gemini), and it was found that their surfactants could lower the IFT of the crude oil-brine surface. Babu et al. ${ }^{19}$ prepared a polymeric surfactant used as the oil recovery agent to reduce the IFT and modify the rock wettability. Kumar et al. $^{20}$ synthesized an anionic surfactant from vegetable oil for oil displacement processes. They found that subsequent modifications in the IFT, wettability, and viscosity improved the final oil recovery through core flood tests. Kumar and Mandal studied the effect of a zwitterionic surfactant on IFT and wettability alteration. ${ }^{21}$

The surfactants in most of the studies mentioned above are toxic and have adverse effects on human health and the environment. ${ }^{22,23}$ Also, in situ surfactant (alkaline) flooding is considered to cause groundwater contamination when there is a risk of leakage through the reservoir pores. However, it is a highly effective oil recovery technology that can reduce the IFT at the oil-water interface. ${ }^{17}$

Recently, environmentally friendly chemicals have drawn attention worldwide as the environmental damage resulting from chemical EOR processes is profoundly severe. ${ }^{22-24}$

The effects of nonionic surfactants on the IFT reduction are lower than the result of cationic or anionic surfactants. ${ }^{25}$ However, nonionic surfactants are environmentally friendly compared to both the cationic surfactants, which are the most toxic to the environment, and the anionic surfactants, as they are sulfonate-based chemicals. ${ }^{26}$ These surfactants are harmful to human health as they damage the liver and cause chronic symptoms. $^{23-28}$ High adsorption of the cationic surfactants restricts their application in the EOR processes. ${ }^{29}$ The high cost of the zwitterionic surfactants is also a restriction for their EOR applications. ${ }^{30,31}$

Based on past studies and chemical analyses of surfactants, it is recommended, during the surfactant flood, to add cosurfactants such as alcohols for the following reasons: they can improve the stability of microemulsions, ${ }^{32}$ enhance the surfactant system to withstand the reservoir conditions, and they are biodegradable. ${ }^{33}$

Bio-based nonionic surfactants were synthesized from two different waste cooking oils in this work, and their application in EOR processes was studied. Based on the surface tension and thermodynamics properties, two surfactants were used for the core flooding tests. The effect of alcohols on the flooding test was also studied, and the surfactant/alcohol ratio (SAR) was determined through IFT tests. The heavy oil recovery results were discussed in light of IFT, wettability alteration, and the alkane carbon number $(\mathrm{ACN})\left(\Pi_{\min }\right)$.

\section{EXPERIMENTAL SECTION}

2.1. Materials. Sigma-Aldrich Co. supplied the following chemicals: 1,4-sorbitan, potassium hydroxide, anhydrous sodium sulfate, sodium metal, sulfuric acid, ethanol, propanol, butanol, pentanol, isopropanol, iso-butanol, iso-pentanol, n- hexane, $n$-octane, $n$-decane, $n$-dodecane, $n$-tetradecane, $n$ hexadecane, and $n$-octadecane. Table S1 shows their physicochemical properties, in Supporting Information.

2.2. Waste Cooking Oils. The palm waste cooking oil (PWCO) with high palmitic acid content and palm kernel waste cooking oil (PKWCO) with high lauric acid content (PKWCO) were collected from local restaurants in Nasr city, Cairo, Egypt. These samples were heated at $105{ }^{\circ} \mathrm{C}$ for 20 min to remove any moisture and then left to cool down at room temperature. Finally, they were purified from any solids by the vacuum filtration process. ${ }^{34,35}$ The fatty acid profiles for these oils according to the results of gas chromatography (GC)-mass spectrometry are shown in Table 1 and Figure S1.

Table 1. Chemical Composition of the Used Cooking Oils

\begin{tabular}{llc}
\multicolumn{1}{c}{ fatty acid } & palm oil & palm kernel oil \\
caprylic acid (8:0) & & 3.3 \\
capric acid(10:0) & & 3.70 \\
lauric acid (12:0) & 0.3 & 48.7 \\
myristic acid (14:0) & 1.2 & 15.4 \\
palmitic acid (16:0) & 47.0 & 9.4 \\
stearic acid (18:0) & 5.2 & 1.5 \\
oleic acid (18:1) & 32.3 & 14.5 \\
linoleic acid (18:2) & 13.2 & 3.2 \\
linolenic acid (18:3) & 0.3 & \\
arachidic acid (20:0) & 0.2 & 0.2 \\
others & 0.3 & 0.1 \\
M.wt. & 268.89 & 211.98
\end{tabular}

2.3. Hydrolysis of the Used Waste Cooking Oils. 1.2 mol $(66 \mathrm{~g}) \mathrm{KOH}$ was dissolved in $290 \mathrm{~mL}$ of ethyl alcohol at $65{ }^{\circ} \mathrm{C}$ with continuous stirring in a flat-bottomed round flask. The used cooking oil $(0.35 \mathrm{~mol})$ was added individually to the reaction flask and then heated to $75{ }^{\circ} \mathrm{C}$ for $2.5 \mathrm{~h}$. Finally, after adding $190 \mathrm{~mL}$ of distilled water, sulfuric acid (3 M) was added gradually with continuous stirring until two layers appeared, and the layers were separated with a separating funnel. The upper layer contained the free hydrolyzed fatty acids of the corresponding oil, ${ }^{36}$ the hydrolyzed palm waste cooking oil (HPWCO) and the hydrolyzed palm kernel waste cooking oil (HPKWCO). The free fatty acid layer was washed several times with hot distilled water until a $\mathrm{pH}$ equal to 7 was attained. Then, the free fatty acids were left overnight on anhydrous sodium sulfate to dry. The product yield was 89.8 gm $(90 \%)$, and the product was an odorless yellow color material.

2.4. Preparation of Nonionic Surfactants Based on Sorbitan. 2.4.1. Monoesterification of Sorbitan with the Hydrolyzable Free Fatty Acids. A round bottom flask (500 $\mathrm{mL}$ ) containing $0.12 \mathrm{~mol} 1,4$-sorbitan and $0.12 \mathrm{~mol}$ hydrolyzed fatty acid from HPWCO or HPKWCO and 0.15 mol sodium hydroxide ( $0.6 \mathrm{~g}$ ) was heated at $140-180{ }^{\circ} \mathrm{C}$ with stirring. Without organic solvent under vacuum to water, withdraw for $3 \mathrm{~h}$ (Figure 1). The monoester was washed with hot water until the $\mathrm{pH}$ reaches $7 .^{36}$ The products were left overnight on anhydrous sodium sulfate to dry. The yields were 96 and 95\% for HPWCO and HPKWCO, respectively.

2.4.2. Ethoxylation of Sorbitan Esters by Ethylene Oxide Adduct Condensation. A round bottom flask $(250 \mathrm{~mL})$ containing $(0.1 \mathrm{~mol})$ sorbitan monoester and a catalytic amount of sodium metal (0.1 wt \%) was heated at $170-180$ 


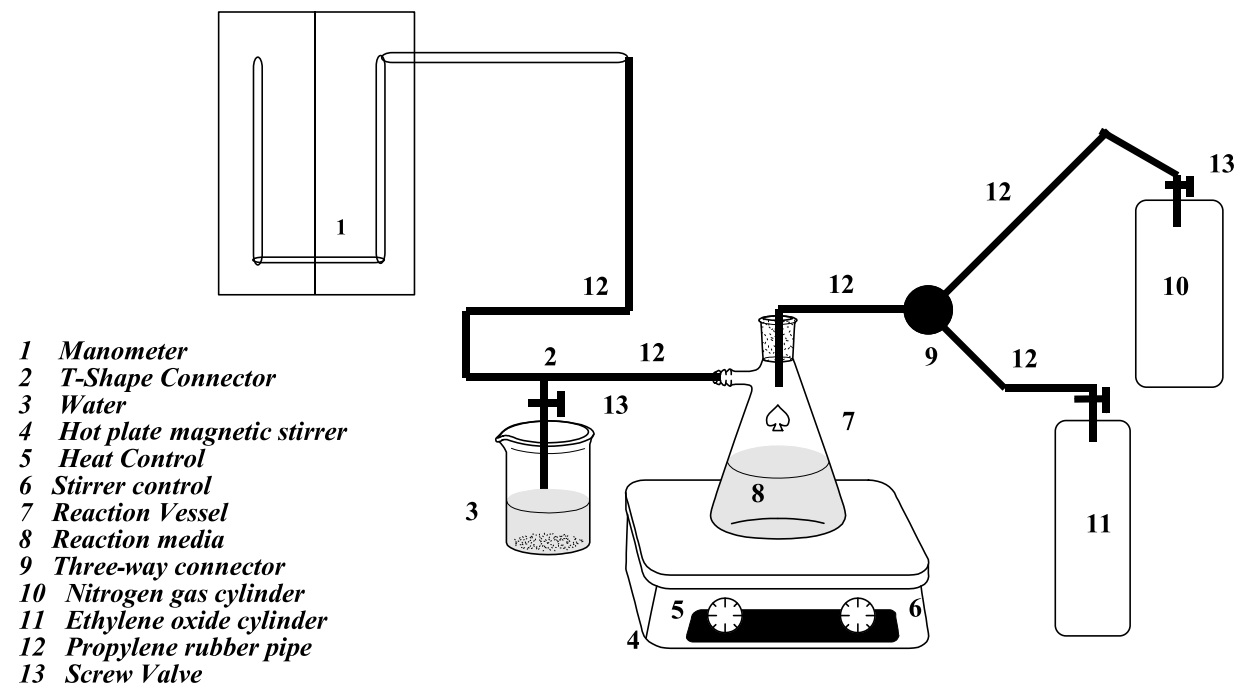

Figure 1. Experimental sketch for ethoxylation process.

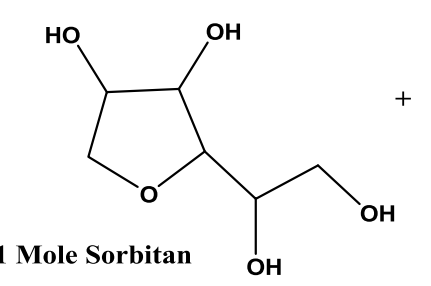

\section{RCOOH \\ 1 Mole HPWCO \\ or \\ 1 Mole HPKWCO}
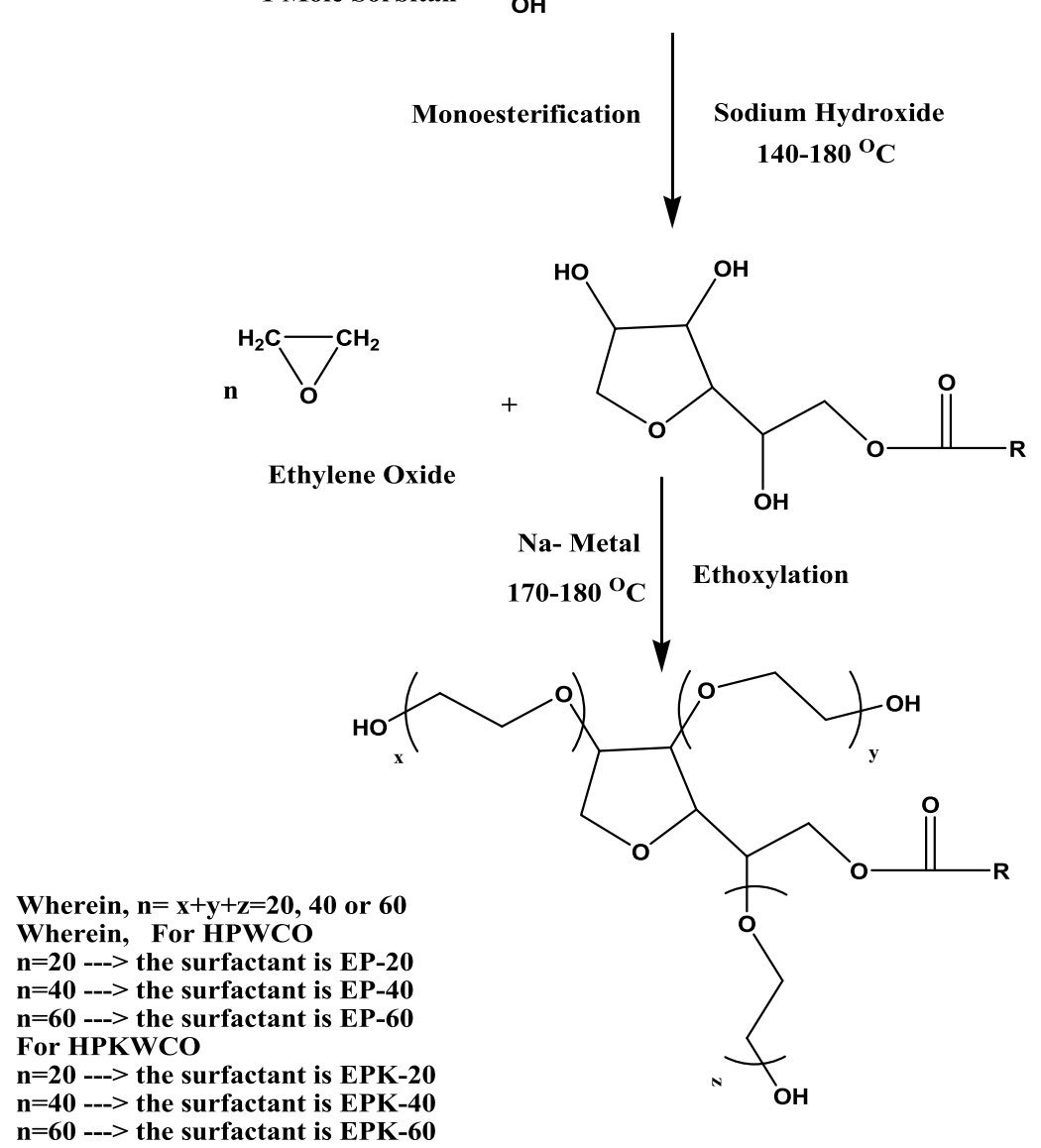

Na- Metal

170-180 ${ }^{\circ} \mathrm{C}$ Ethoxylation<smiles>CCCOCCO</smiles><smiles>[3H][3H]</smiles>

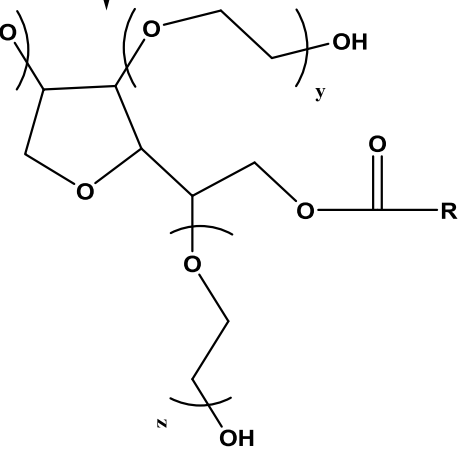

Figure 2. Preparation scheme of monoester ethoxylated sorbitan of HPWCO and HPKWCO.

${ }^{\circ} \mathrm{C}$ with stirring. ${ }^{37}$ To flush out air, nitrogen gas was filled into the system for $5 \mathrm{~min}$. Then, a stream of ethylene oxide was injected into the system instead of the nitrogen gas. This injection process was performed at a fixed rate by controlling the mercury level in the manometer. The added moles of ethylene oxide were determined by carrying the reaction at 
different time intervals, after which nitrogen gas was filled into the apparatus and then cooled and weighed. The detailed experimental sketch is presented in Figure 1.

Dilute $\mathrm{HCl}$ neutralized the final products. Then, the products were dissolved in $50 \mathrm{~mL}$ of isopropanol, followed by salting out using supersaturated $\mathrm{NaCl}$ solution. The last step involves the distillation of the solvent to get purified ethoxylated compounds. ${ }^{37,38}$ The differences in weights indicate the amount of the ethylene oxide units consumed in the reaction; hence, the number of ethylene oxide moles' (n) per mole of the reactants. The average number of ethylene oxide units for the monoester of HPWCO or HPKWCO were about 20, 40, and 60 units (Figure 2). The products were yellowish viscous liquids. FTIR and $\mathrm{H}^{1}$ NMR spectroscopy justified the chemical structure. We calculated the molecular weights and hydrophile-lipophile balance (HLB) and listed them in Table 2.

Table 2. Molecular Weights and HLB of the Nonionic Surfactants

$\begin{array}{ccc}\text { surfactant } & \text { molecular weight } & \text { HLB } \\ \text { EP-20 } & 1295 & 13.5 \\ \text { EP-40 } & 2175 & 16.1 \\ \text { EP-60 } & 3055 & 17.2 \\ \text { EPK-20 } & 1238 & 14.2 \\ \text { EPK-40 } & 2118 & 16.6 \\ \text { EPK-60 } & 2998 & 17.6\end{array}$

2.5. Surface Tension Measurement. The surface tension at the air-water interface of formation water [total dissolved solids (TDS), $\mathrm{mg} / \mathrm{L}$, salinity $\approx 50 \times 10^{3} \mathrm{ppm}$ ] with and without surfactants (different concentrations) was measured at 25, 50, and $70{ }^{\circ} \mathrm{C}$ with Attension Theta High Pressure Chamber. ${ }^{39}$ Table 3 lists the chemical composition of the formation water.

The measurements were repeated three times, and the data were used to calculate the various surface-active and thermodynamic properties.

2.6. IFT and Wettability Alteration Measurement. The IFT of the surfactant solutions at the oil-aqueous interface is an important parameter to evaluate the efficiency of surfactants toward EOR at reservoir conditions. ${ }^{39}$ The IFT between the freshly prepared surfactant solutions at critical micelle concentration (CMC) in the formation water and the crude oil (API, 18 at $60 \mathrm{~F}$; asphaltene, 13.78\%; aromatic, 42.5\%; resin, 25\%; wax, $8.5 \%$ and density, $0.9887 \mathrm{~g} / \mathrm{L}$ ) was measured at different temperatures of 25,50 , and $70{ }^{\circ} \mathrm{C}$. The IFT was measured using Attension Theta High-Pressure Chamber (ASTM ISO 19403-4) in the EPRI EOR unit. The crude oil drop was injected into a capillary tube containing the surfactant solution and allowed to rotate at $3500 \mathrm{rpm}$. The IFT of the blank used oil was $27 \mathrm{mN} \mathrm{m}^{-1}$ at $50{ }^{\circ} \mathrm{C}$. The values of the IFT at the CMC and their effect by branched and nonbranched alcohols were investigated in the study to design the surfactant solution of chemical flooding.
The wettability alteration measurements were conducted using the contact angle (CA) method (sessile drop). ${ }^{39}$ For the CAs of crude oil-brine/surfactant solution-rock, the acquired images were captured using Attension Theta HighPressure Chamber (Sessile Method) (ASTM ISO 19403-5). All measurements (for EPK-20, EP-40, or their hybrid systems with different alcohols) were conducted at a constant temperature of $50{ }^{\circ} \mathrm{C}$ unless stated otherwise.

2.7. Surfactant Flooding Test. The surfactant flooding experiments were carried out using a sand-packed setup with dimensions of $30 \mathrm{~cm}$ in length, $5.0 \mathrm{~cm}$ for internal diameter, and a total bulk volume of $589.28 \mathrm{~cm}^{3}$. The setup was packed with sands with different mesh sizes as porous media to achieve the desired permeability and porosity (mesh size between 1.5 and 3.5 meshes). The mass of the sand in the prepared sand-packed setup was about $700 \mathrm{~g}$. Sands with a size of $0.841-1.68 \mathrm{~mm}$ were used, and the porosity was ranged between 25.10 and $26.68 \%$, and then, the saturation with brine solution was carried out for two days. The process was followed with the injection of about $150 \mathrm{~cm}^{3}$ of oil under reservoir conditions $\left(50{ }^{\circ} \mathrm{C}\right.$ and $\left.2.0 \mathrm{MPa}\right)$ at a rate of $1 \mathrm{~cm}^{3} /$ $\mathrm{min}$, and it was aged for $24 \mathrm{~h}$ at $50{ }^{\circ} \mathrm{C}$. Waterflooding with brine solution (TDS: 50,000 ppm) was performed to determine the oil recovery at the end of the secondary recovery stage, and then it was followed by surfactant flooding (tertiary oil recovery). ${ }^{39,40}$ Figure 3 shows the schematic of the sand-packed setup used for the chemical flooding experiments.

\section{RESULTS AND DISCUSSION}

3.1. Chemical Structure Characterization. The FTIR analysis of the triglyceride waste oil is shown in Figure 4.

The spectra found that the main peak of ester groups is at wavelengths of 1756 and $1109 \mathrm{~cm}^{-1}$. After the hydrolysis process, the FT-IR analysis shows the disappearance of the ester group and the appearance of stretching vibration of the carbonyl group at a wavelength of $1711 \mathrm{~cm}^{-1}$ and an asymmetric vibration of $[\mathrm{C}-\mathrm{O}]$ at a wavelength of $1285 \mathrm{~cm}^{-1}$. For carboxylic acid carbonyl functional groups $(\mathrm{C}=\mathrm{O})$, the FTIR spectrum showed absorption bands of hydrolyzed oil at $1711 \mathrm{~cm}^{-1}$ for stretching vibration and $1282 \mathrm{~cm}^{-1}$ for stretching asymmetric while they were at 1408 and 920$930 \mathrm{~cm}^{-1}$ for bending vibration of carboxylic acid. ${ }^{36}$ The $\mathrm{OH}$ group is evident at $2975 \mathrm{~cm}^{-1}$ in the hydrolyzed oil while it almost disappears in the oil FTIR spectrum and appears again at $2842 \mathrm{~cm}^{-1}$ for the ether bond (-O-) ethoxylated EPK-20.

The $\mathrm{H}^{1}$ NMR spectrum shown in Figure 5 exhibits the peaks of the chemical shifts at $4.2 \mathrm{ppm}$ corresponding to the ester protons $\left(\mathrm{CH}_{2}-\mathrm{COO}-\mathrm{CH}_{2}\right)$ and between 3.5 and 3.8 ppm corresponding to the ethoxylated protons $\left(\mathrm{CH}_{2}-\mathrm{O}-\right.$ $\left.\mathrm{CH}_{2}-\right)$. The fatty chain protons $\left(\mathrm{CH}_{2}-\right)$ also demonstrated their signatures at $1.2-1.5 \mathrm{ppm}$, while the peak associated with terminal methyl group protons $\left(-\mathrm{CH}_{3}\right)$ appeared at 0.7 $\mathrm{ppm}$. The changed features on the spectrum justified the chemical structure.

Table 3. Chemical and Physical Composition of the Used Brine (TDS: 50 and 457 ppm)

\begin{tabular}{|c|c|c|c|c|c|c|c|c|c|c|c|}
\hline \multicolumn{8}{|c|}{ ppm } & \multirow[b]{2}{*}{$\mathrm{pH}$} & \multirow[b]{2}{*}{ turbidity NTU } & \multirow[b]{2}{*}{ density $\mathrm{g} / \mathrm{cm}^{3}$} & \multirow[b]{2}{*}{ conductivity $\mathrm{Ms} / \mathrm{cm}$} \\
\hline $\mathrm{Cl}^{-}$ & $\mathrm{Na}^{+}$ & $\mathrm{K}^{+}$ & $\mathrm{Fe}^{-3}$ & $\mathrm{PO}_{4}^{-3}$ & $\mathrm{SO}_{4}^{-2}$ & $\mathrm{Ca}^{+2}$ & $\mathrm{Mg}^{+2}$ & & & & \\
\hline 17304 & 18058 & 12713 & 0.01 & 0.07 & 188 & 1540 & 1244 & 7.01 & 0.2 & 1.0788 & 154.785 \\
\hline
\end{tabular}




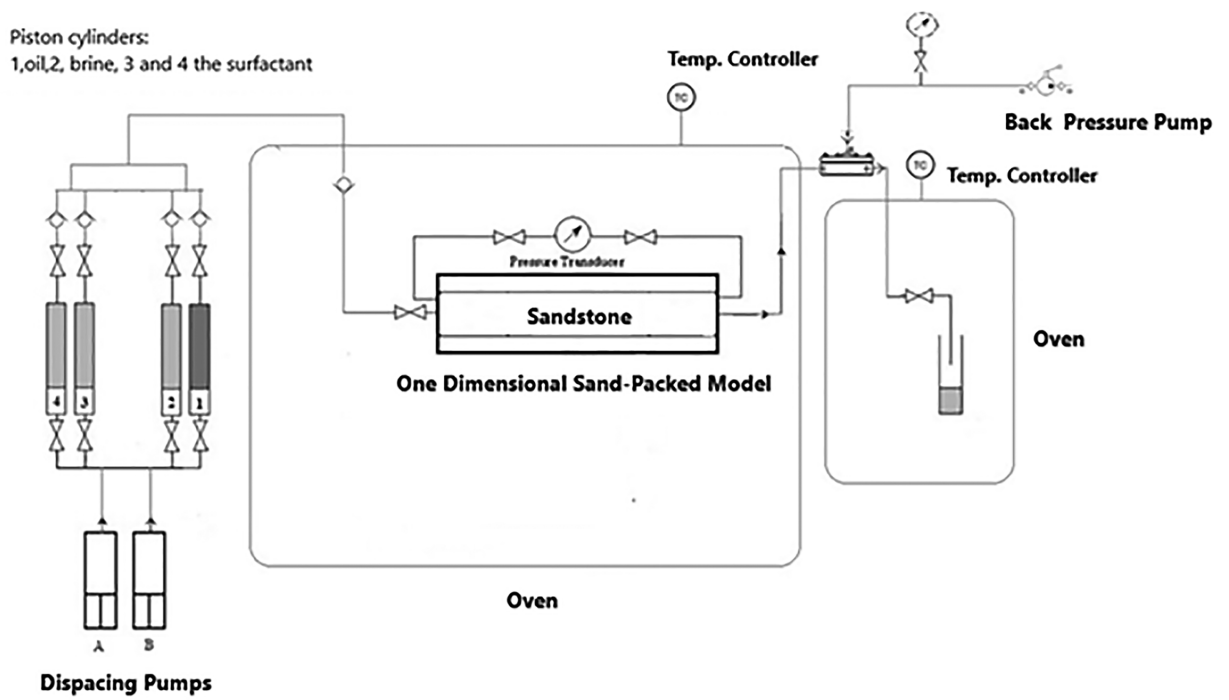

Figure 3. Schematic of the experimental setup used for surfactant flooding tests.

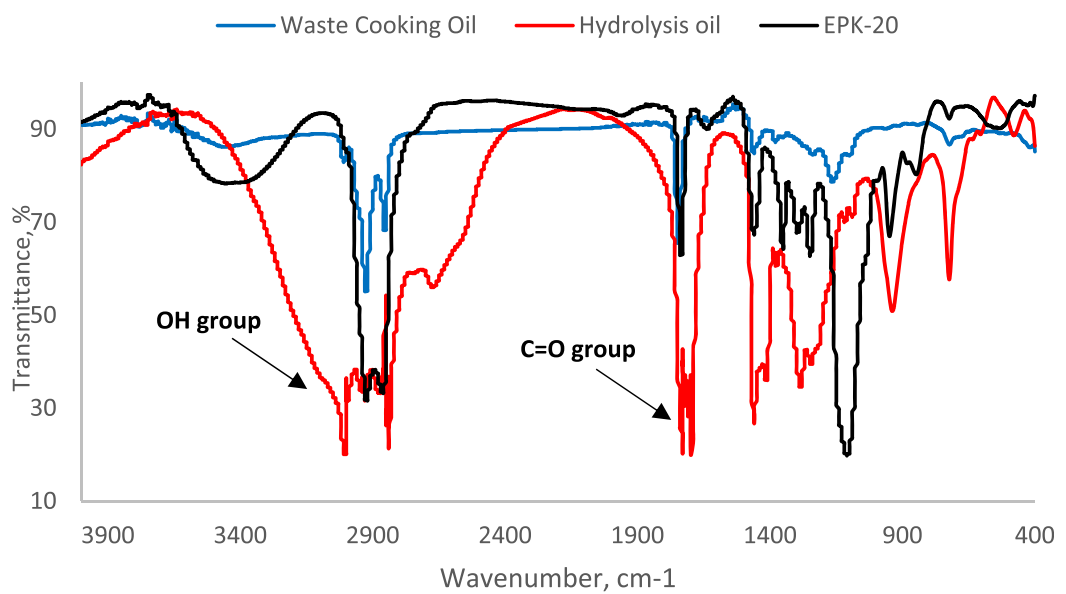

Figure 4. FTIR spectrum of palm kernel waste oil (blue line), the hydrolyzed form of palm kernel waste oil (red line), and EPK-20 (black line).

3.2. Molecular Weights of the Hydrolyzed Fatty

Acids. The molecular weights of the final surfactants were calculated theoretically based on the molecular weight of the oil, that is, a relative proportion of different fatty acids in the oil (Table 2). The oil was converted into alcohol esters (methyl) of fatty acid for determining the fatty acids. Their molecular weights were determined by the composition profile of fatty acids as shown earlier in Figure $\mathrm{S} 1$ and Table 1 . The average molecular weight of the fatty acid mixture was calculated by dividing the sum of all reported fatty acid weights, from GC, by the total moles in the mix, numerically, $^{36}$

the average molecular weight of fatty acids

$$
=\sum \mathrm{fi} / \sum\left(\frac{\mathrm{fi}}{\mathrm{MWi}}\right)
$$

where fi is the weight fraction of the reported fatty acid.

\subsection{Surface Tension and Thermodynamic Properties} of the Surfactants. The surface tension of synthesized nonionic surfactants was measured at 25,50 , and $70{ }^{\circ} \mathrm{C}$ in the formation water. The surface tension versus $-\ln C$ isotherm is shown in Figure 6. By comparing the CMC values with the number of ethylene oxide units, as shown in Table 4, the results showed that the increase of temperature leads to a rise in the CMC value due to the decomposition of the hydrogen bonds. Consequently, this decreases the coiling of the ethylene oxide chain, which leads to an increase in the solubility of the surfactant molecule. The CMC results show that ethoxylate sorbitol of the hydrolyzed fatty acid esters of waste oils can effectively saturate any interface. The surface adsorption attributes good low IFT to be applied in EOR. The surfactant molecules lower the surface tension, contributing to a quantitative investigation that shows continuous adsorption on the interface. Therefore, the possibility of micelles formation is not entirely formed at a concentration less than the CMC. It is evident from Table 4 that the CMC for the EP derivatives ranged between $2.2 \times 10^{-3}$ and $2.9 \times 10^{-2} \mathrm{~mol} / \mathrm{L}$ at $50{ }^{\circ} \mathrm{C}$, while that for the EPK derivatives ranged between $2.9 \times 10^{-3}$ and $1.6 \times 10^{-2} \mathrm{~mol} / \mathrm{L}$ at $50{ }^{\circ} \mathrm{C}$. This increase of CMC values may be because the HLB of the EPK group is higher than the HLB of the EP group, which further increases the CMC.

As the results of the main composition of the palm oil depend on palmitic acid (47\%) and oleic acids (32\%) but those of the kernel palm oil depend on lauric (48.7\%) and myristic acids (15.4\%), as shown in Table 1, the hydrophobic character of these acids have a direct effect on the HLB of the 
(a)

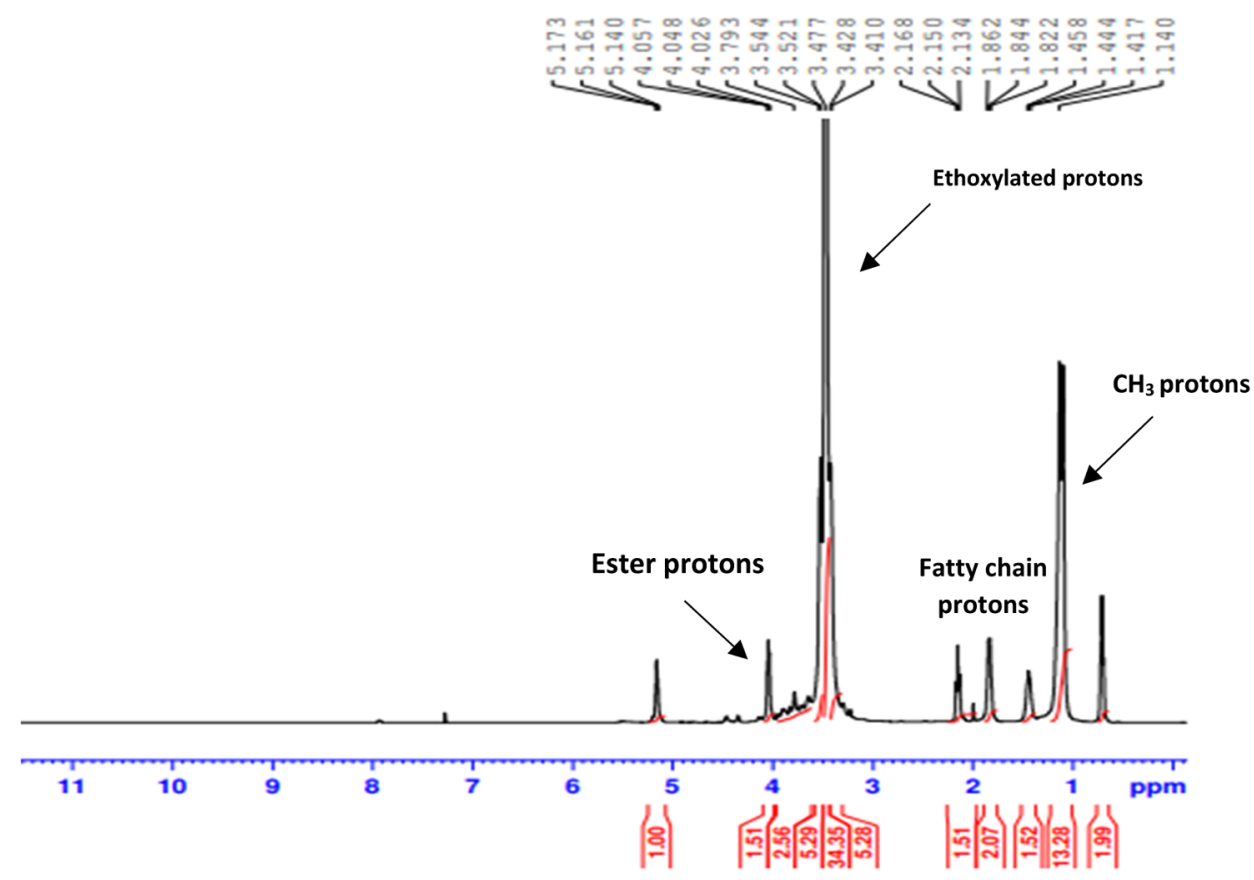

(b)
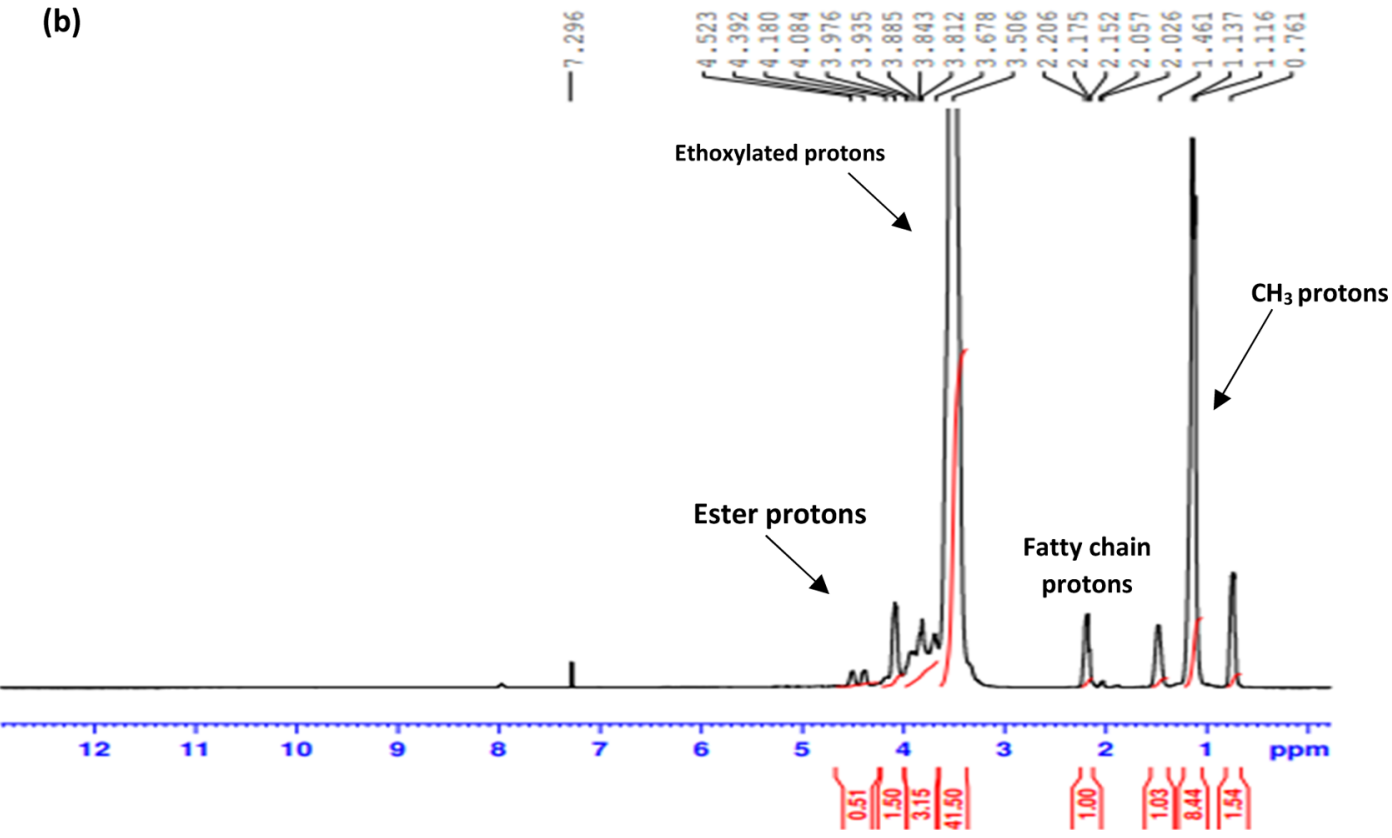

Figure 5. $\mathrm{H}^{1}$ NMR spectrum of (a) EPK-20 and (b) EP-40.

final ethoxylated sorbitol esters. The $\gamma_{\mathrm{CMC}}$ values of the hydrolyzed palm oil derivatives (EP) are situated between 36 and $30 \mathrm{mN} \mathrm{m}^{-1}$. However, for the kernel palm oil derivatives (EPK), the $\gamma_{\mathrm{CMC}}$ values were 35 to $26 \mathrm{mN} \mathrm{m}^{-1}$ along the course of temperature and different ethylene oxide units. EPK20 exhibited the most reduction in the surface tension $(31,28$, and $26 \mathrm{mN} \mathrm{m}^{-1}$ ) against temperatures 25,50 , and $70{ }^{\circ} \mathrm{C}$, respectively. Meanwhile, EP-40 achieved the most reduction of surface tension $\left(34,32\right.$, and $\left.30 \mathrm{mN} \mathrm{m}^{-1}\right)$ against 25,50 , and $70{ }^{\circ} \mathrm{C}$, respectively. These results put these two surfactants in the front to use for further investigation in the EOR applications.

The effectiveness $\left(\pi_{\mathrm{CMC}}\right)$ is the difference between the surface tension values of the formation water only and with surfactant solution in the formation water at the CMC and different temperatures, it can be determined by the following eq 2

$$
\left(\pi_{\mathrm{CMC}}\right)=\gamma_{\mathrm{w}}-\gamma_{\mathrm{s}}
$$

where $\gamma_{\mathrm{w}}$ is the surface tension of the formation water and $\gamma_{\mathrm{s}}$ is the surface tension of surfactant solution in the formation water at the CMC. By calculating the average value of $\pi_{\mathrm{CMC}}$, the results showed that the maximum surface excess concentration $\pi_{\mathrm{CMC}}$ is the maximum amount up to which surfactant adsorption can be obtained at the surface. This depends on the molecular structures of the interacting component. The degree of adsorption was calculated by Gibbs isotherm and is given by the following eq 3 . 
(a)

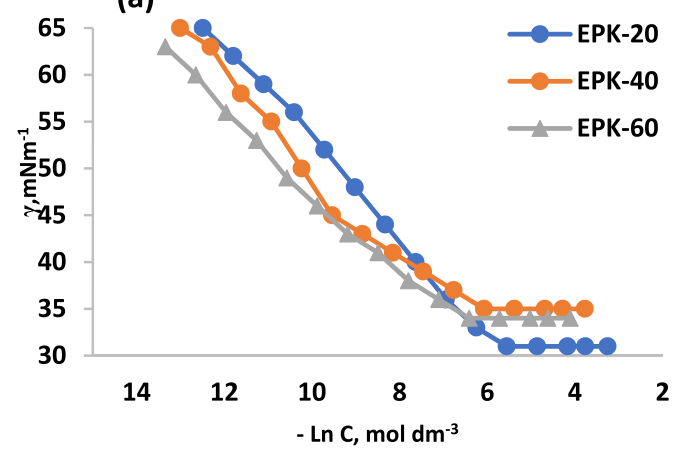

(c)

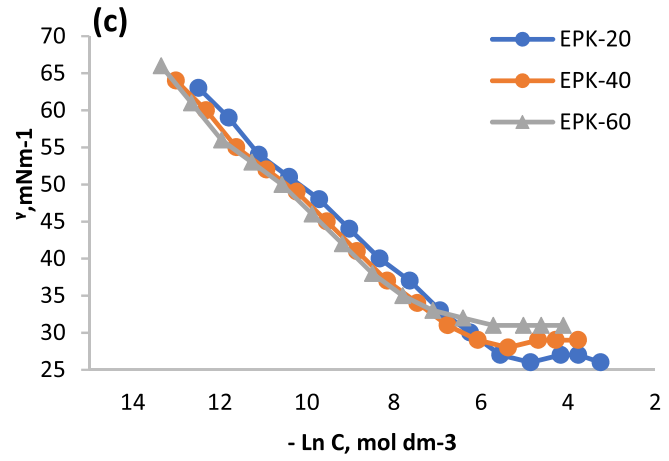

(e)

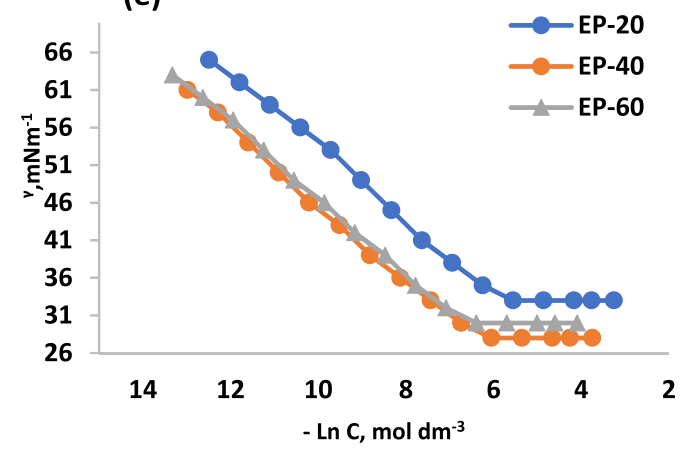

(b)

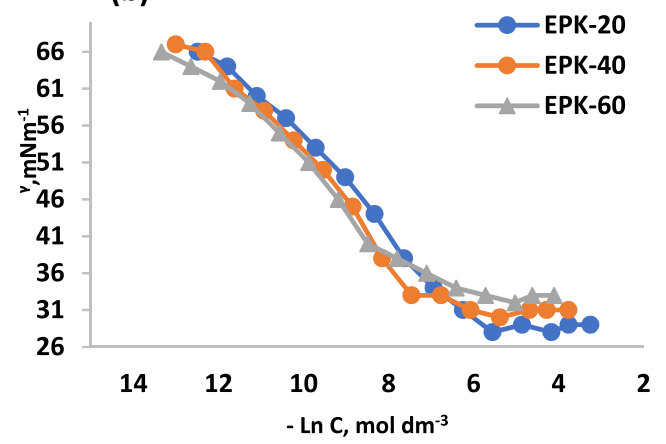

(d)

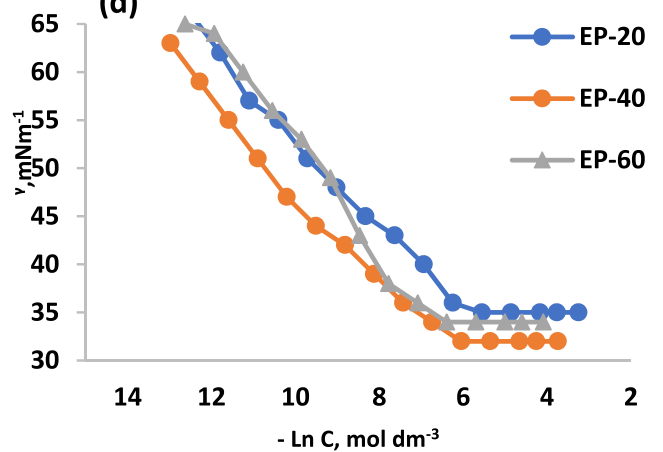

(f)

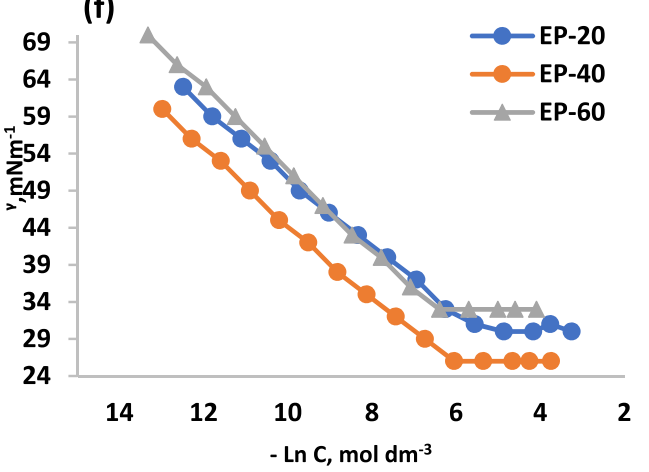

Figure 6. Surface tension vs $-\ln C$ isotherm for EPK-20 at (a) 25, (b) 50, and (c) $70{ }^{\circ} \mathrm{C}$ and EP-40 at (d) 25 , (e) 50 , and (f) $75{ }^{\circ} \mathrm{C}$.

$$
\Gamma_{\max }=-\left(\frac{1}{R T}\right) \times \frac{\delta \gamma}{\delta \ln C}
$$

where $\Gamma_{\max }$ is the surface excess concentration $\mathrm{mol} \mathrm{cm}{ }^{-2}, T$ is the absolute temperature, $R$ is the universal gas constant $\left(8.314 \mathrm{~J} \mathrm{~mol}^{-} \mathrm{K}^{-1}\right.$ ), and $\frac{\delta \gamma}{\delta \ln C}$ is the slope of $\gamma-\ln C$ (preCMC). $A_{\min }$ was calculated by eq 4

$$
A_{\min }=\frac{10^{16}}{N \cdot \Gamma_{\max }}
$$

where $N$ is Avogadro's number $\left(6.022 \times 10^{23}\right)$.

The selectivity of the surfactant is based on reducing surface tension and the area per molecule $\left(A_{\min }\right)$. The $A_{\min }$ values showed a slight increment by increasing temperature. The decrease and increase in $\Gamma_{\max }$ values may be due to the thermal agitation that results from the repulsion forces between the bulk phase molecules. The repulsion forces are based on the breaking of hydrogen bonds in the bulk phase. ${ }^{38}$
The results of surface tension were used to calculate the micellization and adsorption free energies at the interfaces. At equilibrium conditions, the decrease in the surface tension is due to the adsorption of surfactant molecules at the interface. The adsorption amount of surfactant molecules at the interface per unit area was provided by Gibbs adsorption.

The data in Table 4 show the $\Delta G_{\text {mic }}$ and $\Delta G_{\text {ads }}{ }^{\prime}$ calculated values for the prepared surfactants at different temperatures. The negative values of $\Delta G_{\text {mic }}$ indicated the formation of micelles in the bulk phase of the solution. This finding indicates that micellization is a spontaneous associationdissociation process that occurs at the interface. Simultaneously, the negative values of $\Delta G_{\text {mic }}$ increase the free energy of solvent, which compensates the surfactant molecules to prefer adsorption on the surface and interface before forming the micelles. The negative values of $\Delta G_{\text {mic }}$ also indicated that the adsorption of the surfactant molecules at the interface is also a spontaneous process.

The more negative values of $\Delta G_{\mathrm{ads}}$, are due to the increase of the curvature of an aqueous surface. Consequently, the 
Table 4. Surface-Active and Thermodynamics Properties of the Synthesized Surfactants at 25,50 , and $70{ }^{\circ} \mathrm{C}$

\begin{tabular}{|c|c|c|c|c|c|c|c|c|}
\hline sample & temp. ${ }^{\circ} \mathrm{C}$ & $\mathrm{CMC} \times 10^{-3}(\mathrm{~mol} / \mathrm{L})$ & $\gamma_{\mathrm{CMC}}\left(\mathrm{mN} \mathrm{m}^{-1}\right)$ & $\Gamma_{\max } \times 10^{-10}\left(\mathrm{~mol} / \mathrm{cm}^{2}\right)$ & $A_{\min }, \mathrm{nm}^{2}$ & $\pi_{\mathrm{CMC}} \mathrm{mN} \mathrm{m}^{-1 a}$ & $\Delta G_{\text {mic }}(\mathrm{kJ} / \mathrm{mol})$ & $\Delta \mathrm{G}_{\mathrm{ads}}(\mathrm{kJ} / \mathrm{mol})$ \\
\hline \multirow[t]{3}{*}{ EPK-20 } & 25 & $1.2 \times 10-^{3}$ & 31 & 1.82 & 91 & 36 & -16.4 & -18.7 \\
\hline & 50 & $2.2 \times 10-^{3}$ & 28 & 1.65 & 100 & 37 & -16.7 & -18.9 \\
\hline & 70 & $2.4 \times 10-^{3}$ & 26 & 1.61 & 103 & 38 & -17.2 & -19.6 \\
\hline \multirow[t]{3}{*}{ EPK-40 } & 25 & $1.8 \times 10^{-2}$ & 33 & 1.77 & 94 & 34 & -9.9 & -11.9 \\
\hline & 50 & $1.9 \times 10^{-2}$ & 31 & 1.67 & 99 & 34 & -10.6 & -12.5 \\
\hline & 70 & $2.6 \times 10^{-2}$ & 29 & 1.63 & 102 & 35 & -10.9 & -12.9 \\
\hline \multirow[t]{3}{*}{ EPK-60 } & 25 & $2.2 \times 10^{-2}$ & 35 & 1.69 & 98 & 32 & -8.9 & -10.8 \\
\hline & 50 & $2.9 \times 10^{-2}$ & 34 & 1.63 & 102 & 31 & -9.4 & -11.3 \\
\hline & 70 & $4.5 \times 10^{-2}$ & 33 & 1.54 & 108 & 31 & -9.9 & -11.7 \\
\hline \multirow[t]{3}{*}{ EP-20 } & 25 & $1.2 \times 10^{-2}$ & 35 & 1.68 & 99 & 32 & -10.8 & -12.9 \\
\hline & 50 & $1.6 \times 10^{-2}$ & 33 & 1.61 & 103 & 32 & -11.0 & -13.0 \\
\hline & 70 & $2.2 \times 10^{-2}$ & 32 & 1.55 & 107 & 32 & -11.2 & -13.4 \\
\hline \multirow[t]{3}{*}{ EP-40 } & 25 & $2.2 \times 10^{-3}$ & 34 & 1.76 & 94 & 33 & -15.1 & -17.0 \\
\hline & 50 & $2.9 \times 10-^{3}$ & 32 & 1.69 & 98 & 33 & -15.3 & -17.4 \\
\hline & 70 & $4.8 \times 10-^{3}$ & 30 & 1.57 & 105 & 34 & -15.9 & -17.6 \\
\hline \multirow[t]{3}{*}{ EP-60 } & 25 & $1.1 \times 10^{-2}$ & 36 & 1.71 & 97 & 31 & -10.9 & -13.3 \\
\hline & 50 & $1.2 \times 10^{-2}$ & 34 & 1.65 & 100 & 31 & -11.2 & -13.6 \\
\hline & 70 & $2.2 \times 10^{-2}$ & 33 & 1.50 & 110 & 31 & -11.7 & -14.1 \\
\hline
\end{tabular}

number of available vacancy sites for adsorption on the surface increases, and more surfactant molecules should be adsorbed at the surface or interface with temperature elevation, as shown in Table 4.

As the results achieved, it can be expected that these surfactants should be pronounced stable emulsions at the CMC. The negative values of $\Delta G_{\text {mic }}$ and $\Delta G_{\text {ads }}$, which give thermodynamic stability to the expected bulk emulsion phase, further exhibited effective interfacial interaction with the surrounding media. ${ }^{38-41}$ Based on surface tension results, EPK-40 and EP-20 should form proper formulations to solubilize the heavy oil in the emulsion form. The emulsion improves the oil displacement during the surfactant flooding process.

3.4. IFT in the Term of the ACN. Table 5 summarizes the IFT properties of EP-40 and EPK-20 at different

Table 5. IFT and CA of the Heavy Oil in the Presence of Formation Brine, EPK-20, and EP-40 at $50{ }^{\circ} \mathrm{C}$

\begin{tabular}{lccc}
$\begin{array}{c}\text { heavy oil in the } \\
\text { presence of }\end{array}$ & $\begin{array}{c}\text { concentration, } \\
\text { wt } \%\end{array}$ & $\begin{array}{c}\text { IFT } \\
\left(\mathrm{mN} \mathrm{m}^{-1}\right)\end{array}$ & $\begin{array}{c}\text { static CA } \\
(\theta)\end{array}$ \\
formation brine & & 17.92 & 161.45 \\
EPK-20 & 0.2 & 0.08 & 36.81 \\
& 0.4 & 0.06 & 27.5 \\
& 0.6 & 0.09 & 29.97 \\
0.8 & 0.13 & 32.98 \\
1.0 & 0.15 & 34.01 \\
& 0.2 & 0.15 & 39.84 \\
EP-40 & 0.4 & 0.18 & 39.04 \\
& 0.6 & 0.11 & 36.42 \\
& 0.8 & 0.09 & 32.63 \\
1.0 & 0.15 & 35.46 \\
\hline
\end{tabular}

concentrations at $50{ }^{\circ} \mathrm{C}$. From the results, EP-40 achieved the lowest IFT $\left(0.09 \mathrm{mN} \mathrm{m}^{-1}\right)$ at $0.8 \mathrm{wt} \%$ conc. (equivalent CMC), while EPK-20 (conc. 0.4 wt \%) achieved the lowest IFT $\left(0.06 \mathrm{mN} \mathrm{m}^{-1}\right)$ due to their molecular structure and components.

Before applying the surfactants to EOR processes, their spinning ACNs should be determined at the CMC concentration. The $\mathrm{ACN}$ is determined by measuring the IFT of the surfactant solution (EPK-20 and EP-40) against the $n$-alkane series $\left(n-\mathrm{C}_{6}\right.$ to $\left.n-\mathrm{C}_{16}\right)$, as shown in Figure 7 . This scan of the IFT introduces the spinning alkane model in the form of a V-like shape to determine $\Pi_{\text {min }}$. $\Pi_{\text {min }}$ is the ACN at which the surfactant exhibited minimum IFT. ${ }^{42-46}$ In this work, the ACN in the form of an equivalent carbon number of crude oil (EACN) was determined by the GC hydrocarbon profile, as shown in Figure S2. The used heavy crude oil showed that it contains a total $n$-hydrocarbon equal to $n$ - $\mathrm{C}_{14}$. The determination of the EACN for the used heavy crude oil and $\Pi_{\min }$ for the surfactant might help imagine the matching between the EACN of the oil and $\Pi_{\min }$ of surfactants. The minimum reduction of the IFT should be achieved at the matching between these two terms, which gives a high probability to form stable oil-in-water (O/W) emulsions during the surfactant flooding process, which in turn will facilitate in achieving optimum oil recovery.

Figures 7 and 8 show the $n$-alkane scan that has been carried out for EPK-20 and EP-40 at the CMC. The minimum tensions were obtained and changed regarding the change of the $n$-alkane. From the V-like shape curves, it can be detected the EACN, $\Pi_{\min }$, and $\gamma_{\min }$. The $\gamma_{\min }$ and $\Pi_{\min }$ for EP-40 were $0.06 \mathrm{mN} \mathrm{m}^{-1}$ and 10 respectively where the EPK-20 exhibited $\gamma_{\min }$ equal $0.02 \mathrm{mN} \mathrm{m}^{-1}$, and $\Pi_{\min }$ is 12 .

These data mean that the surfactant molecules at the CMC are sufficient to cause Gibbs monolayer adsorption, and consequently, the surfactant molecules can form an emulsion. So, the maximum efficiency of the surfactants is achieved at the CMC or slightly above the CMC. Simultaneously, the increase of the surfactant concentration more than the CMC may cause two adverse effects. ${ }^{19-21}$ The first is not an economic factor in the EOR application, and the second is the multilayer adsorption at the interface, which may hinder the development of the emulsion. Further, the production of the oil should be negatively affected.

It is crucial to match $\Pi_{\text {min }}$ of the surfactant with the EACN of the used crude oil in the EOR study. In this work, $\Pi_{\min }$ of the best surfactants were 12 and 10 for EPK-20 and EP-40, respectively, while the EACN of the crude oil was 14 . So, the 

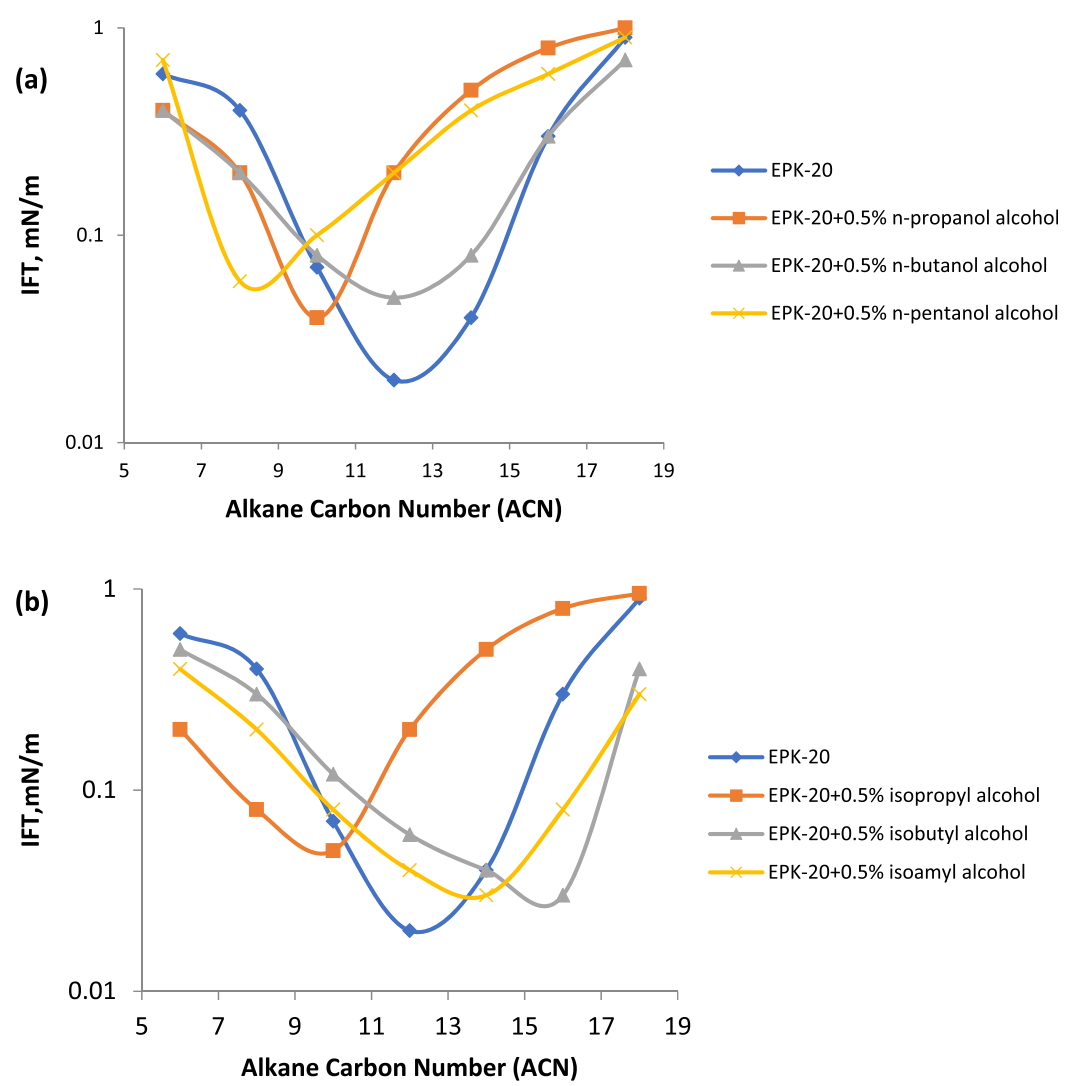

Figure 7. Relation between IFT and alkyl chain number (ACN) for (a) EPK-20 with nonbranched alcohols and (b) EPK-20 with branched alcohols.
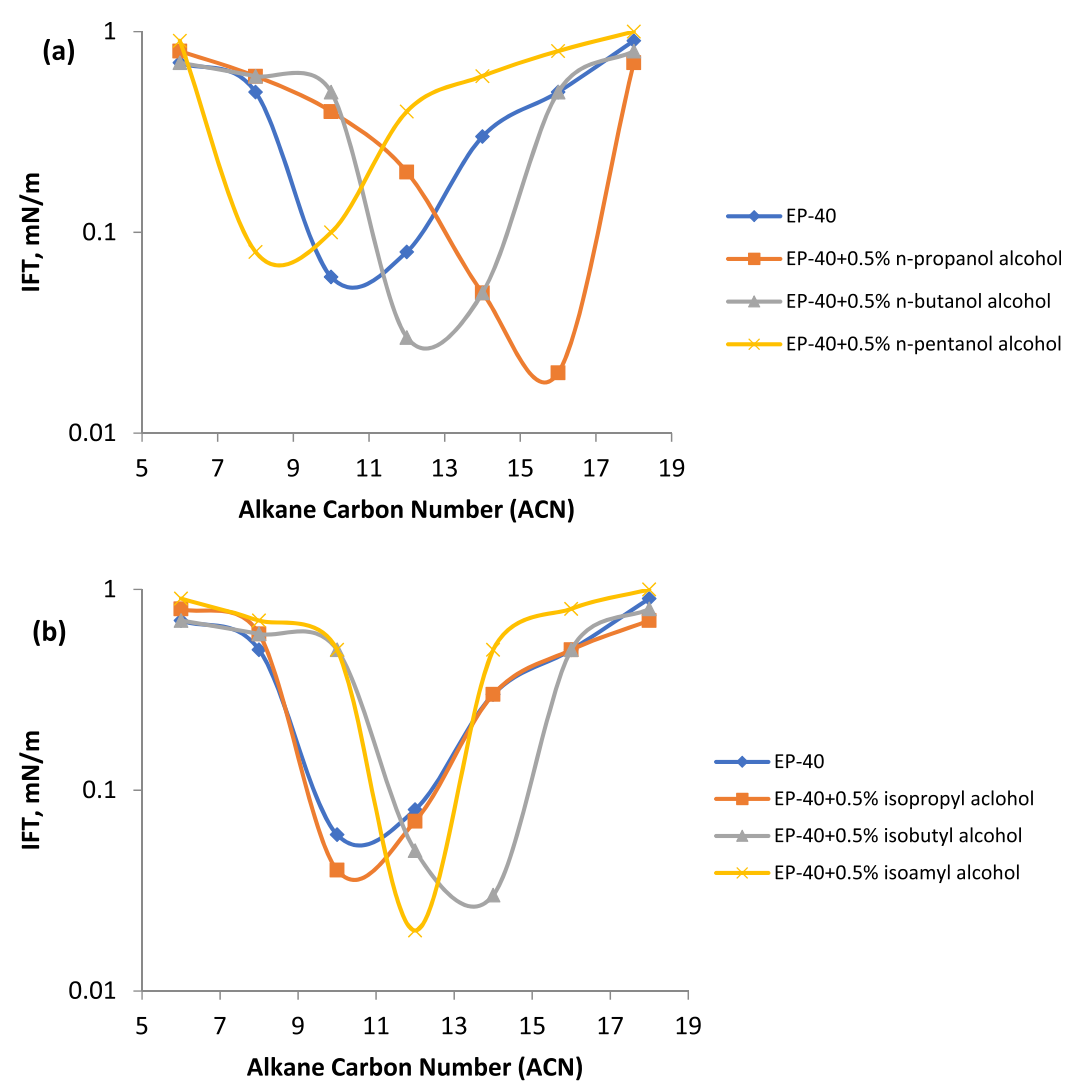

Figure 8. Relation between IFT and alkyl chain number ACN for (a) EP-40 with nonbranched alcohols and (b) EP-40 with branched alcohols. 
Table 6. Effect of Straight and Branched Alcohols on the IFT at $50{ }^{\circ} \mathrm{C}$

\begin{tabular}{|c|c|c|c|c|c|c|c|c|c|c|}
\hline \multirow[b]{2}{*}{ surfactant } & \multirow[b]{2}{*}{ concentration, wt $\%$} & \multicolumn{3}{|c|}{ iso-propyl alcohol } & \multicolumn{3}{|c|}{ iso-butyl alcohol } & \multicolumn{3}{|c|}{ isoamyl alcohol } \\
\hline & & 0.1 & 0.5 & 1 & 0.1 & 0.5 & 1 & 0.1 & 0.5 & 1 \\
\hline EPK-20 & 0.4 & 0.06 & 0.05 & 0.08 & 0.05 & 0.04 & 0.07 & 0.04 & 0.02 & 0.05 \\
\hline EP-40 & 0.8 & 0.07 & 0.06 & 0.1 & 0.06 & 0.02 & 0.09 & 0.05 & 0.05 & 0.08 \\
\hline \multirow[b]{2}{*}{ surfactant } & \multirow[b]{2}{*}{ concentration, wt \% } & \multicolumn{3}{|c|}{$n$-propanol alcohol } & \multicolumn{3}{|c|}{$n$-butanol alcohol } & \multicolumn{3}{|c|}{ n-pentanol alcohol } \\
\hline & & 0.1 & 0.5 & 1 & 0.1 & 0.5 & 1 & 0.1 & 0.5 & 1 \\
\hline EPK-20 & 0.4 & 0.07 & 0.06 & 0.2 & 0.06 & 0.04 & 0.09 & 0.08 & 0.06 & 0.2 \\
\hline EP-40 & 0.8 & 0.09 & 0.07 & 0.2 & 0.07 & 0.05 & 0.1 & 0.09 & 0.08 & 0.3 \\
\hline
\end{tabular}

formulation of the chemical flood should be designed with some additives such as alcohols. These alcohols can shift $\Pi_{\min }$ to a high value to match $\Pi_{\text {min }}$ of the surfactant and the EACN of the crude oil.

3.5. Effect of Alcohols on the IFT and ACN. The alcohols are cosolvents, and their hydrophobicity or hydrophilicity plays an essential role in minimizing the IFT.

Alcohols shift $\Pi_{\min }$ to the low or high values, as shown in Table 6, and the effects of straight (normal) and branched alcohols on $\gamma_{\text {min }}$ for EPK-20 are shown in Table 7 and Figure

Table 7. $\gamma_{\min }$ and $\Pi_{\min }$ Shifts of $0.5 \%$ Alcohol and $0.4 \%$ of EPK-20 ${ }^{a}$

$\begin{array}{lccc}\text { alcohol, } 0.5 \% & \gamma_{\min }{ }^{*} 10^{-2} & \Pi_{\min }^{*} & \Pi_{\min } \text { shift }^{a} \\ n \text {-propanol } & 4 & 10 & -2 \\ n \text {-butanol } & 5 & 12 & 0 \\ \text { n-pentanol } & 6 & 8 & -4 \\ \text { iso-propyl } & 5 & 10 & -2 \\ \text { iso-butyl } & 3 & 16 & +4 \\ \text { iso-amyl } & 3 & 14 & +2\end{array}$

${ }^{a}$ The ACN of the used crude oil is 14 , and $\Pi_{\min }$ of EPK-20 is 12 . The $(-)$ and $(+)$ signs point to the decrease or increase of $\Pi_{\min }$ by the corresponding values.

7 at the $\mathrm{CMC}$ at $50{ }^{\circ} \mathrm{C}$. Straight alcohols shifted $\Pi_{\min }$ to a lower value for EPK-20 $\left(\Pi_{\min }=12\right)$ to $n_{10}(-2)$ against propanol, $n_{12}(0)$ against butanol, and $n_{8}(-4)$ against pentanol in which the $\gamma_{\min }$ values were $4 \times 10^{-2}, 5 \times 10^{-2}$, and $6 \times 10^{-2}$, respectively (Table 7 ). In branched alcohols, isoamyl alcohol exhibited a complete fit with EPK-20 as it matched with the EACN of the crude oil $\left(n-\mathrm{C}_{14}\right)$. As this results, the formulations (EPK-20 at the $\mathrm{CMC}+0.5 \%$ isoamyl alcohol) should be tested in the chemical flood process in this work.

The effect of the same alcohols on $\gamma_{\min }$ and $\Pi_{\min }$ of EP-40 is shown in Table 8 and Figure 8. From the obtained data, it was

Table 8. $\gamma_{\min }$ and $\Pi_{\min }$ Shifts of $0.5 \%$ Alcohol and $0.8 \%$ of EP-40 ${ }^{a}$

$\begin{array}{lccc}\text { alcohol, } 0.5 \% & \gamma_{\min }{ }^{*} 10^{-2} & \Pi_{\min }{ }^{*} & \Pi_{\min } \text { shift }^{a} \\ n \text {-propanol } & 2 & 16 & +6 \\ n \text {-butanol } & 3 & 12 & +2 \\ \text { n-pentanol } & 8 & 8 & -2 \\ \text { iso-propyl } & 4 & 10 & 0 \\ \text { iso-butyl } & 3 & 14 & +4 \\ \text { iso-amyl } & 2 & 12 & +2\end{array}$

${ }^{a}$ The ACN of the used crude oil is 14 , and $\Pi$ min of EP-40 is 10 . The $(-)$ and $(+)$ signs point to the decrease or increase of $\Pi_{\min }$ by the corresponding values. found that $n$-propanol only shifted $\Pi_{\min }$ to a higher value (+6), $n$-butanol also shifted $\Pi_{\min }$ to a higher value $(+2)$, and $n$-pentanol shifted $\Pi_{\min }$ to a lower value $(-2)$. However, the shift caused by branched alcohols was $0,+4$, and +2 against isopropanol, iso-butanol, and isoamyl alcohols, respectively.

The complete matching in $\Pi_{\min }$ and the EACN of the used crude oil was achieved with $0.5 \%$ iso-butanol $\left(n_{14}\right)$, not with the isoamyl alcohol as in the case of EPK-20. This behavior may be due to the HLB of EP-40 that equals 16.1, but the HLB of EPK-20 equals 14.2. The molecule needs more hydrophobic alcohols to solubilize to match the EACN of the used crude oil $(n=14)$. As this results, the formulation from iso-butanol and EP-40 at the CMC was also tested in the chemical flooding process.

The dynamic IFT is a significant factor in expecting the adsorption of the surfactant on the interface. The dynamic IFT was carried out for EPK-20 at the CMC with $0.5 \%$ isoamyl alcohol and without alcohol and for EP-40 at the $\mathrm{CMC}$ with $0.5 \%$ iso-butanol and without alcohol. Figure 9

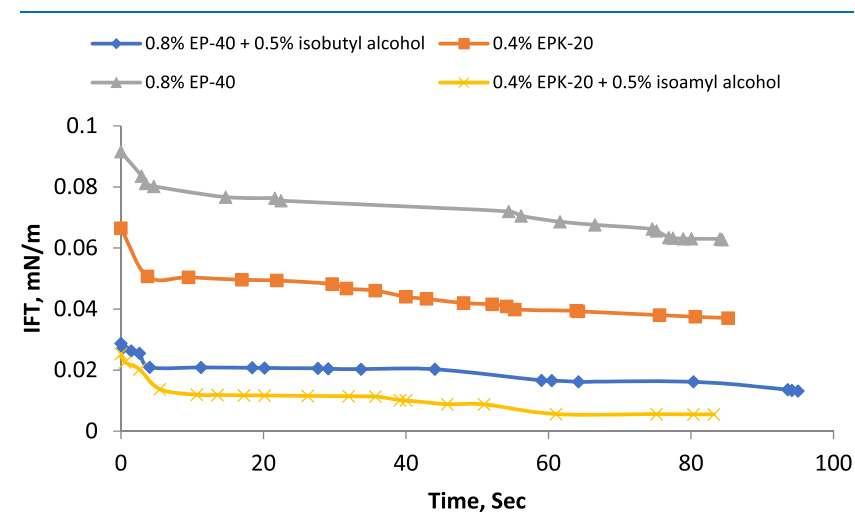

Figure 9. IFT of EPK-20 and EP-40 in the presence of $0.5 \%$ alcohol at $50{ }^{\circ} \mathrm{C}$.

shows the dynamic IFT for the two surfactants. The curve was stable at a steady state up to $100 \mathrm{~s}$. This means that after forming a monolayer, more and more surfactant molecules penetrate to solubilize the oil at the interface to form a waterin-oil emulsion; further, the recovery factor (RF) should be increased. This finding led us to expect that the formulation is an essential factor in the EOR application.

3.6. CAs and Wettability Alteration. The CAs for the heavy crude oil on the sandstone rock samples with and without alcohols in the surfactant formulations (EPK-20 and EP-20) is shown in Figure 10.

The CA of the oil droplet is $161.45^{\circ}$, and it changes to $27.5^{\circ}$ by adding EPK-20 (0.4\%), while it becomes $32.63^{\circ}$ when $0.8 \%$ of EP-40 is used (Table 5). This means that the rock sample was altered from an oil-wet to a water-wet 


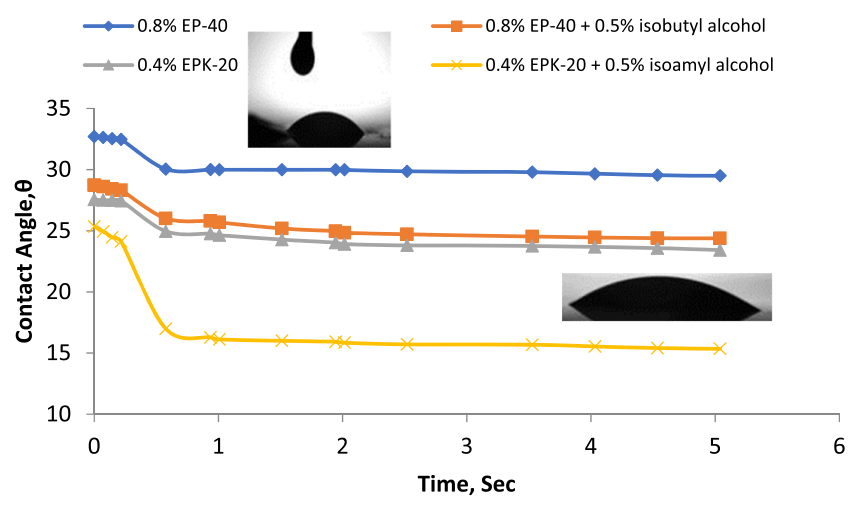

Figure 10. CAs of EPK-20 and EP-40 in the presence of 0.5 wt \% alcohol at $50{ }^{\circ} \mathrm{C}$.

condition from the measured CAs. The addition of the surfactant at the CMC reduces the IFT and CA. It is evident from the data in Table 5 that it can result in reducing the capillary forces. This assists the displacement process in an oil recovery process when lower viscous forces due to lower adhesion forces are needed for separating the oil drops from the rock surface and mobilize the oil in the form of an emulsion.

Generally, the addition of the cosurfactant into the surfactant flooding formulations decreases the dynamic CA. This may be explained by the fact that the oil droplet is less stable and easier to break when the surfactant/cosurfactant is introduced. ${ }^{47-49}$

In this study, the presence of the surfactant turns the surface of the oil droplet (oil layer in the pores of the rocks) to more hydrophilic as a result of monolayer adsorption, which tends to form an $\mathrm{O} / \mathrm{W}$ emulsion (low viscosity), which consequently improves the efficiency of the EOR process.

3.7. Surfactant Flooding Tests. 3.7.1. RFs of EPK-20 and EP-40. A successful surfactant flooding process to enhance the oil recovery needs proper design of the surfactant slug at an optimum concentration. The flooding process depends on many factors such as the CMC, adsorption properties on sand packed, IFT, CA, and alteration of wettability at the rock surface. From the point of view of the used crude oil equivalent ACN (EACN) and surfactant, these factors were discussed here.

The relation between the IFT and the percent of recovered oil is presented in Figure 11a. For EPK-20 (the blue bars), the maximum oil recovery (the orange line) is achieved with the lowest IFT (the blue bars) at $0.4 \%$ concentration. The same conclusion can be drawn for EP-40 (the green bars) at a concentration of $0.8 \%$. As shown in Figure $11 \mathrm{~b}$, it was confirmed that the maximum oil recovery (the orange line) is achieved with the lowest CA value (bar chart) at a concentration of 0.4 and 0.8 wt \% for EPK-20 and EP-40, respectively. Table 9 lists the details of flooding experiments for different concentrations of EPK-20.

After the surfactant solution flooding, the trapped oil in the pores is mobilized due to the decrease in the IFT between the oil and the injecting surfactant solution. Therefore, the surfactant solution can interact with the trapped oil and solubilize it by forming $\mathrm{O} / \mathrm{W}$ emulsions while benefiting from the wettability alteration of the rock. Figure 12 shows the morphology of the emulsions for EPK-20 and EP-40, immediately after the flooding and at the completion of flooding.

Based on the data provided in Table 9, it can be concluded that EPK-20 achieved the maximum oil recovery of $54.4 \%$ at a concentration of $0.4 \%$ (at the CMC of EPK-20). This is
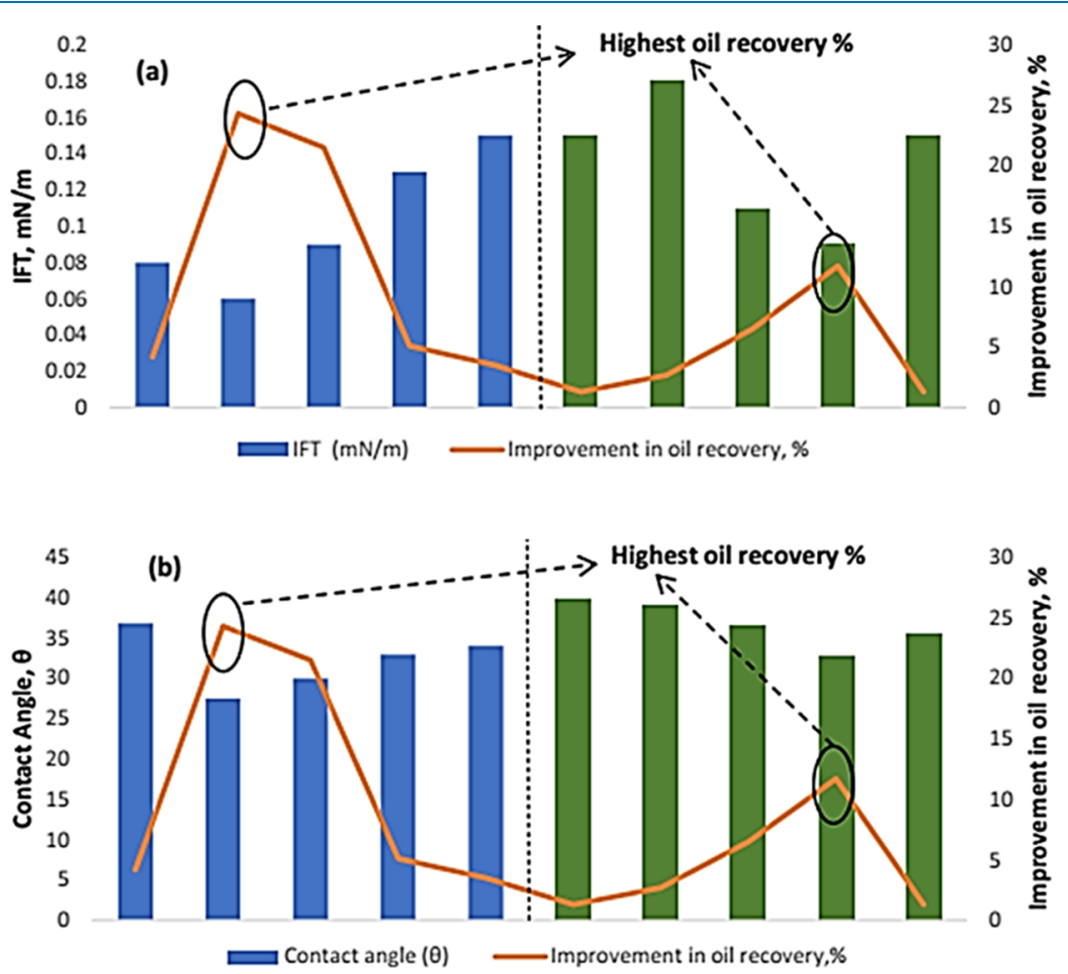

Figure 11. Relation between improvement in tertiary oil recovery and (a) IFT and (b) CA at various concentrations of EPK-20 and EP-40 (the blue bars represent EPK-20, while the green bars represent EP-40). 
Table 9. Surfactant Flooding Tests Using the sand-packed model at $50{ }^{\circ} \mathrm{C}$ and $2.0 \mathrm{MPa}$

\begin{tabular}{|c|c|c|c|c|c|c|}
\hline $\begin{array}{l}\text { run } \\
\text { no. }\end{array}$ & $\begin{array}{l}\text { porosity } \\
(\%)\end{array}$ & $\begin{array}{l}\text { initial oil } \\
\text { saturation }(\%)\end{array}$ & $\begin{array}{l}\text { secondary } \\
\text { recovery }(\%)\end{array}$ & run composition & $\begin{array}{l}\text { incremental oil recovery by } \\
\text { surfactant flooding (\%) }\end{array}$ & $\begin{array}{l}\text { total recovery } \\
(\%)\end{array}$ \\
\hline 1 & 25.10 & 87.6 & 32.5 & 0.2 wt \% EPK-20 & 4.2 & 36.7 \\
\hline 2 & 25.71 & 87.2 & 30.1 & 0.4 wt $\%$ EPK-20 & 24.3 & 54.4 \\
\hline 3 & 25.33 & 87.5 & 31.4 & 0.6 wt $\%$ EPK-20 & 21.5 & 52.9 \\
\hline 4 & 25.56 & 88.1 & 32.7 & 0.8 wt $\%$ EPK-20 & 5.1 & 37.8 \\
\hline 5 & 25.41 & 87.4 & 33.2 & 1.0 wt $\%$ EPK-20 & 3.5 & 36.7 \\
\hline 6 & 25.68 & 87.9 & 31.7 & 0.2 wt $\%$ EP-40 & 1.3 & 33.0 \\
\hline 7 & 25.73 & 87.4 & 30.4 & 0.4 wt $\%$ EP-40 & 2.7 & 36.9 \\
\hline 8 & 25.23 & 88.3 & 34.7 & 0.6 wt $\% \mathrm{EP}-40$ & 6.5 & 41.2 \\
\hline 9 & 26.14 & 87.7 & 35.2 & 0.8 wt $\% \mathrm{EP}-40$ & 11.7 & 46.9 \\
\hline 10 & 26.37 & 88.2 & 30.4 & 1.0 wt $\% \mathrm{EP}-40$ & 1.3 & 31.7 \\
\hline 11 & 25.71 & 87.9 & 33.5 & $\begin{array}{l}0.4 \text { wt } \% \text { EPK- } 20+0.5 \text { wt } \% n- \\
\text { propanol alcohol }\end{array}$ & 27.3 & 60.8 \\
\hline 12 & 26.41 & 88.7 & 34.2 & $\begin{array}{l}0.4 \text { wt } \% \text { EPK- } 20+0.5 \text { wt } \% n \text {-butanol } \\
\text { alcohol }\end{array}$ & 26.5 & 60.7 \\
\hline 13 & 25.37 & 87.4 & 30.5 & $\begin{array}{l}0.4 \text { wt } \% \text { EPK- } 20+0.5 \text { wt } \% \text { n-pentanol } \\
\text { alcohol }\end{array}$ & -2.5 & 28.0 \\
\hline 14 & 25.32 & 88.1 & 34.3 & $\begin{array}{l}0.8 \text { wt } \% \text { EP- } 40+0.5 \text { wt } \% n \text {-propanol } \\
\text { alcohol }\end{array}$ & 14.2 & 48.5 \\
\hline 15 & 26.43 & 87.9 & 34.5 & $\begin{array}{l}0.8 \text { wt } \% \text { EP- } 40+0.5 \text { wt } \% n \text {-butanol } \\
\text { alcohol }\end{array}$ & 17.6 & 52.1 \\
\hline 16 & 25.19 & 87.1 & 30.2 & $\begin{array}{l}0.8 \text { wt \% EP-40 + } 0.5 \text { wt \% n-pentanol } \\
\text { alcohol }\end{array}$ & -4.3 & 25.9 \\
\hline 17 & 25.75 & 88.5 & 34.9 & $\begin{array}{l}0.4 \text { wt \% EPK- } 20+0.5 \text { wt \% isopropyl } \\
\text { alcohol }\end{array}$ & 26.1 & 61 \\
\hline 18 & 25.91 & 87.1 & 32.4 & $\begin{array}{l}0.4 \text { wt } \% \text { EPK- } 20+0.5 \text { wt \% isobutyl } \\
\text { alcohol }\end{array}$ & 30.7 & 63.1 \\
\hline 19 & 25.42 & 87.7 & 30.1 & $\begin{array}{l}0.4 \text { wt \% EPK- } 20+0.5 \text { wt \% isoamyl } \\
\text { alcohol }\end{array}$ & 36.1 & 66.2 \\
\hline 20 & 26.24 & 87.8 & 35.1 & $\begin{array}{l}0.8 \text { wt } \% \text { EP- } 40+0.5 \text { wt \% isopropyl } \\
\text { alcohol }\end{array}$ & 17.3 & 52.4 \\
\hline 21 & 26.41 & 87.6 & 35.3 & $\begin{array}{l}0.8 \text { wt } \% \text { EP-40 + } 0.5 \text { wt \% isobutyl } \\
\text { alcohol }\end{array}$ & 22.3 & 57.6 \\
\hline 22 & 26.37 & 87.8 & 30.4 & $\begin{array}{l}0.8 \text { wt } \% \text { EP- } 40+0.5 \text { wt \% isoamyl } \\
\text { alcohol }\end{array}$ & 18.8 & 52.7 \\
\hline
\end{tabular}
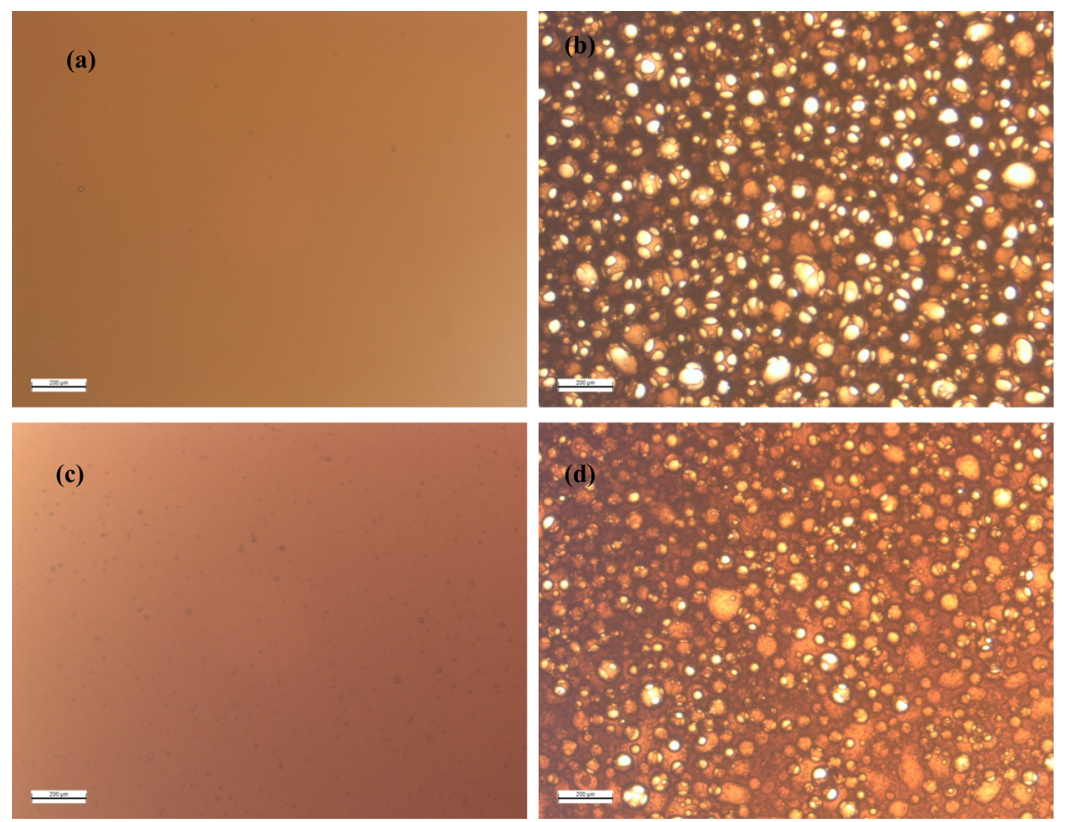

Figure 12. shows the morphology of the emulsions for EPK-20 (a) at the beginning of flooding and (b) at the end of flooding and for EP-40 (c) at the beginning of flooding and (d) at the end of flooding (this was investigated by optical microscopy using a Carl Zeiss Axiovert 40 MAT microscope).

because the adsorption of surfactant molecules at the interface develops a stable electric double layer on the rock surface. At the same time, the IFT is minimum which means that at the $\mathrm{CMC}$, the maximum solubilization of oil by surfactant can be 

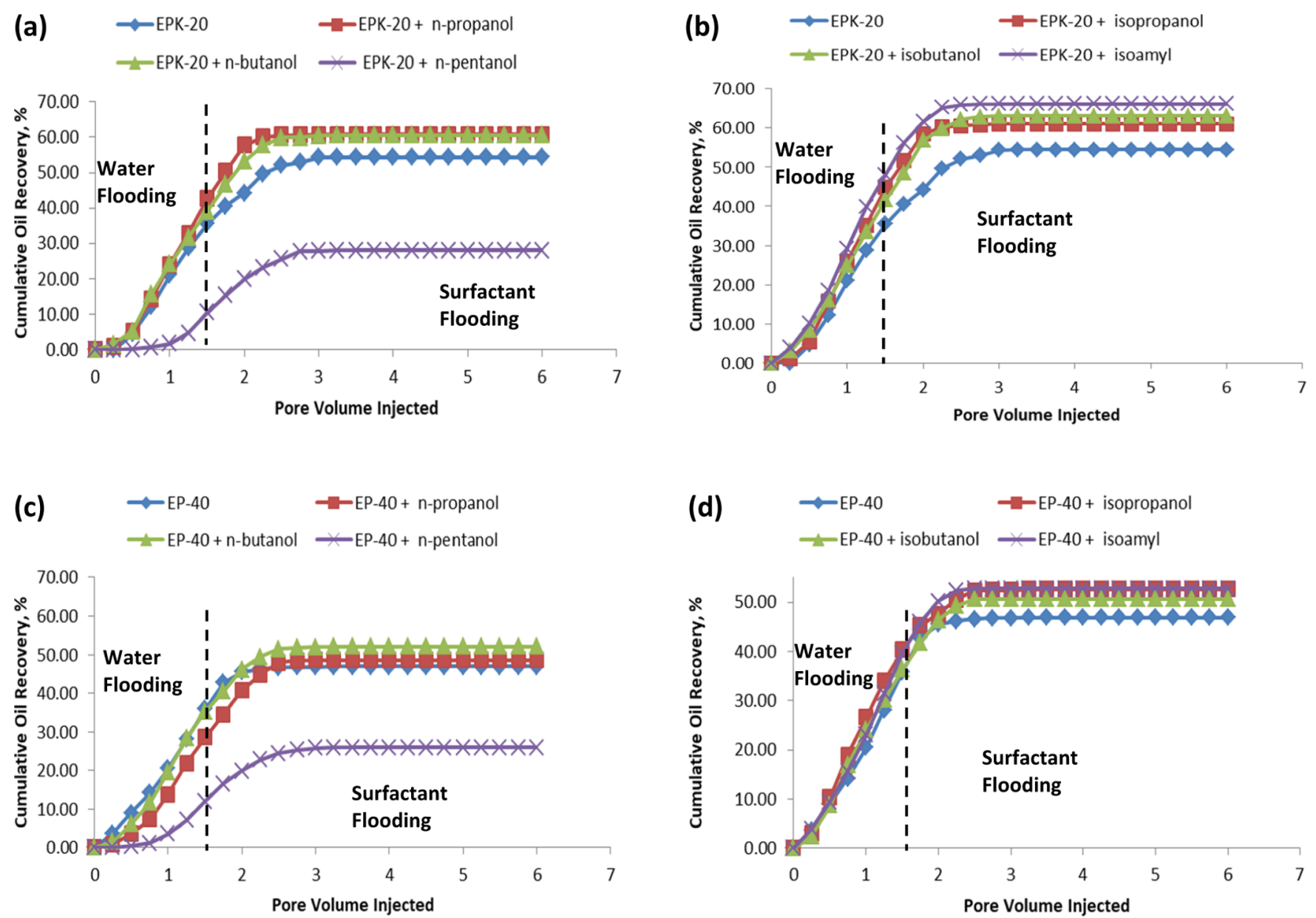

Figure 13. Effects of different alcohols on the surfactant flooding experiments: (a) EPK-20/straight alcohol, (b) EPK-20/branched alcohol, (c) EP-40/straight alcohol, and (d) EP-40/branched alcohol (the steady state reached by water flooding was neglected from the chart).

achieved. At a higher concentration than the CMC, the increase of the surfactant molecules leads to formation of the surfactant adsorption multilayer, which may tend to make inverse emulsions that reflects in decreasing the oil recovery. The improved RF of EPK-20 was $24.3 \%$ for producing the capped oil remaining of the secondary recovery by the formation water only.

From the results shown in Table 9, it is evident from the five experiments that the maximum oil recovery (46\%) with the EP-40 solutions was achieved at $0.8 \mathrm{wt} \%$ conc. (equivalent $\mathrm{CMC}$ ). The incremental RF was $11.7 \%$. The difference between the incremental oil RFs of EPK-20 and EP40 (at their CMC) could be due to their chemical compositions. This can be explained by the HLB of EPK-20 (HLB: 14.2) and EP-40 (HLB: 16.1) and their $\Pi_{\min }$ (ACNs) concerning the EACNs that are 12 and 10 for EPK-20 and EP-40, respectively. The RF mentioned above for these surfactants did not approach the maximum unless their $\Pi_{\min }$ value was close to the EACN of the crude oil. Therefore, straight and branched alcohols were used to improve the incremental RF for the surfactant slug.

3.7.2. Effect of Alcohols on the EOR. Based on the collected IFT results shown in Tables $6-8$, the alcohols were used to minimize the IFT and shift $\Pi_{\min }$ of the surfactant to a higher value to match the EACN of the crude oil. Six sets of flooding experiments were carried out with EPK-20 at the optimum concentration (0.4\%) using $n$-alcohol and branched alcohols.

The same sets of experiments were also designed for EP-40 at $0.8 \%$ concentration after reviewing the oil RF results shown in Table 9. It was found that as all branched alcohols decreased the IFT, they shifted $\Pi_{\min }$ toward the EACN.

Figure 13 and Table 9 summarizes the results of the surfactant flooding experiments when alcohols were used. Branched alcohols exhibited better performance in oil recovery compared to straight alcohols. We have to highlight that before surfactant flooding processes, water flooding was considered. The maximum oil recovery was around 1.5 PV. When the surfactant or surfactant/alcohol mixture was injected up to $6 \mathrm{PV}$ at $2.5 \mathrm{PV}$, there was no significant amount of oil recovered which is due to the creation of a monolayer of surfactant molecules around the oil droplets. After this monolayer was created entirely, a reduction in the IFT and CA mobilizes the oil from the pores. Among branched alcohols, isoamyl alcohol exhibited the best oil recovery of $66.2 \%$ (incremental oil recovery of $36.1 \%$ ) with EPK-20. This result is $11.8 \%$ more than the surfactant flooding when EPK-20 was used with no alcohol. In comparison, isobutyl gave the highest oil recovery of $57.6 \%$ (incremental oil recovery of $22.3 \%$ ) with EP-40. This is around $10.6 \%$ more than the surfactant flooding when EP-40 was used with no alcohol. 

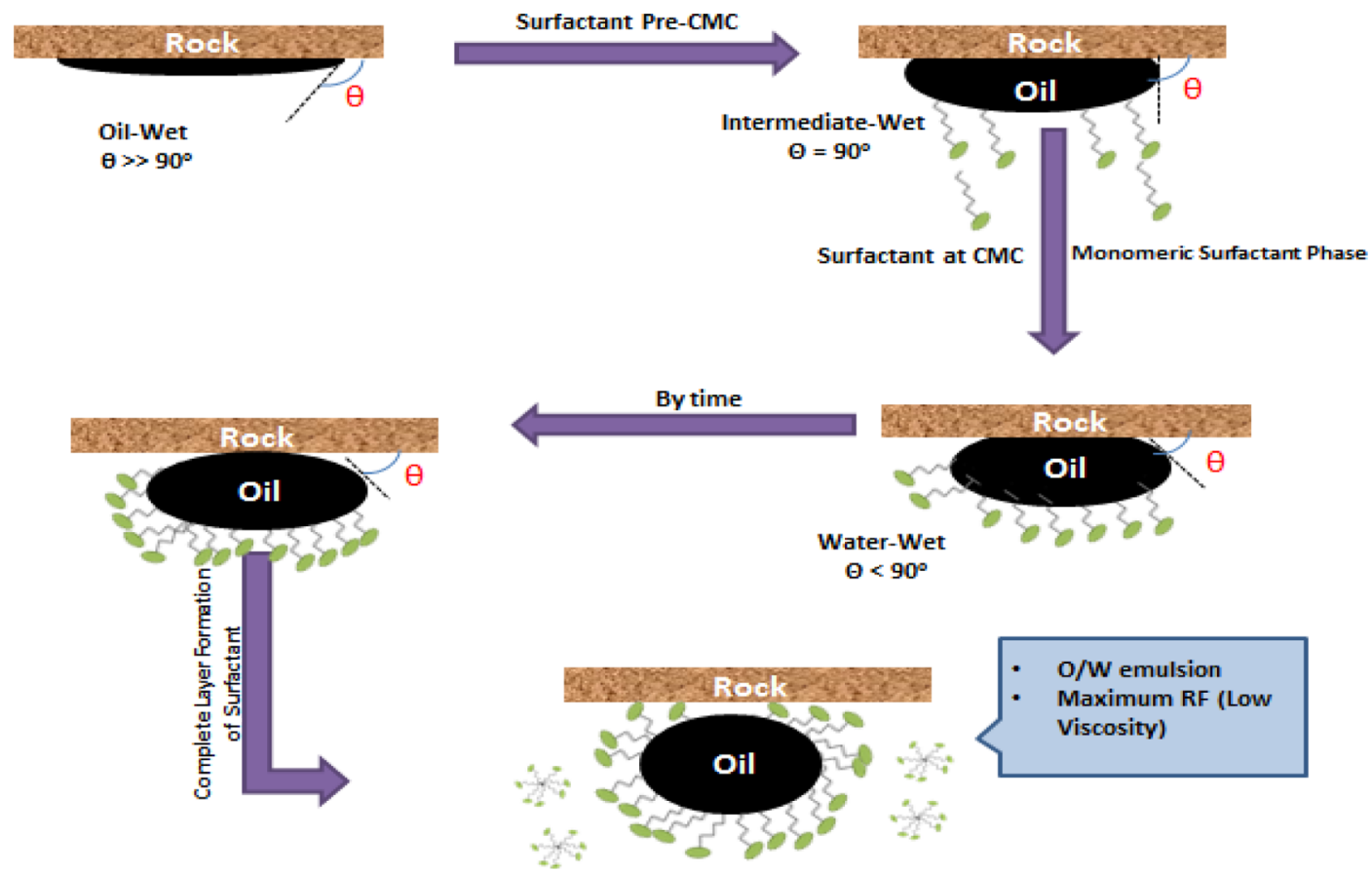

Figure 14. Mechanism of EOR by changing the CA and IFT.

In the case of straight alcohols, $n$-propanol exhibited the highest oil recovery of $60.8 \%$ with EPK-20. This is just 3\% more than the EPK-20 injection. While $n$-butanol produced about $52.1 \%$ with EP-40, and this is $5.9 \%$ more than the injection of EP-40 alone. n-pentanol had a negative effect when it was used with both surfactants as the oil produced was less by 26.8 and $16 \%$ for EPK-20 and EP-40, respectively. This could be attributed to the solubility of pentanol with the surfactant solution that does not allow to solubilize the heavy oil to form oil-in-water emulsion at the crude oil EACN (EACN14).

3.7.3. Mechanism of Oil Recovery. The mechanism of oil recovery improvement in the light of wettability alteration and IFT is shown in Figure 14. In the first stage, the oil droplet is attached to the oil-wet rock surface $\left(\theta \gg 90^{\circ}\right)$. In the second stage, surfactant presence at pre-CMC, the surfactant starts to create a monomeric layer around the trapped oil droplet (surfactant molecules start adsorbing on the oil surface). At this stage, the CA decreases slightly whereas, the surface is still oil-wet $\left(\theta>90^{\circ}\right)$. In the third stage (at the CMC of the surfactant), the complete monolayer of the adsorbed surfactant is formed. The surfactant molecules penetrate between the rock and the oil interface to minimize the IFT. Therefore, the penetrated surfactant molecules build a stable layer between the oil droplets and the rock surface, which decreases the CA further $\left(\theta \leq 90^{\circ}\right)$, which is called an intermediate wettability. The dynamic IFT will reach its minimum value at the final stage, and the CA will be very low $\left(\theta \ll 90^{\circ}\right)$. The rock becomes water-wet where a complete monolayer of adsorbed surfactant molecules and a double layer are formed. After that, the $\mathrm{O} / \mathrm{W}$ emulsions are formed that can move easily through the pore throats, and the final $\mathrm{RF}$ reached its maximum.

\section{CONCLUSIONS AND RECOMMENDATIONS}

Biosurfactants based on waste cooking oils were prepared, and their performance for surfactant flooding processes was investigated. Their chemical structure and surface-active properties were investigated to find the reflection of their property on the efficiency of enhanced heavy oil recovery. EPK-20 achieved the minimum surface tension, $28 \mathrm{mN} \mathrm{m}^{-1}$, and exhibited $\gamma_{\min }$ equal to $0.02 \mathrm{mN} \mathrm{m}^{-1}$, and its corresponding $\Pi_{\min }$ was 12 (The EACN of the used crude oil was 14). Isoamyl alcohol exhibited the complete fit with EPK-20 to match with the EACN of the crude oil ( $n$-C14), while iso-butanol fits more with EP-40. The IFT was reduced from 0.06 to $0.02 \mathrm{mN} \mathrm{m}^{-1}$ by adding isoamyl alcohol to EPK20, while the IFT decreased from 0.09 to $0.02 \mathrm{mN} \mathrm{m}^{-1}$ by adding iso-butanol to EP-40. From the interfacial tension studies, the surfactant/alcohol ratio was 0.4 to $0.5 \mathrm{wt} \%$ for EPK-20/isoamyl alcohol, while the surfactant/alcohol ratio for EP-40/iso-butanol was 0.8 to 0.5 wt \%. The mixture of EP$40 /$ iso-butanol reduces the CA from $32.6^{\circ}$ (EP-40 only) to $28.37^{\circ}$. The CA was reduced from $27.5^{\circ}$ (EPK-20 only) to $25.3^{\circ}$ by the EPK-20/isoamyl alcohol mixture. Branched alcohols and isoamyl alcohol exhibited the best oil recovery of 66.2\% (incremental RF of $36.1 \%$ ) with EPK-20. This is $11.8 \%$ more than injecting EPK-20 alone. Isobutyl alcohol gave the highest oil RF of $57.6 \%$ (incremental oil RF of $22.3 \%$ ) with EP-40. This is around $10.6 \%$ more than EP-40 alone. Meanwhile, in the case of straight alcohols, n-propanol exhibited the best performance for oil recovery with an RF of $60.8 \%$ (incremental oil RF of $27.3 \%$ ) with EPK-20. This is just $3 \%$ more than the EPK-20 injection. $n$-butanol produced about $52.1 \%$ of the oil (incremental oil RF of $17.6 \%$ ) with EP40 , and this is $5.9 \%$ more than the injection of EP-40 alone.

In this study, we used a combination of prepared surfactants and alcohols; therefore, the following are some recommendations for further research:

- Comparison between the prepared surfactants and the commercial ones.

- Conducting more experiments to give a deeper investigation of the produced emulsion during the flooding. 


\section{ASSOCIATED CONTENT}

\section{s) Supporting Information}

The Supporting Information is available free of charge at https://pubs.acs.org/doi/10.1021/acsomega.1c01373.

Details of the physiochemical properties of the used chemicals, GC graphs of the waste oils, and GC analysis graph of the used heavy crude oil (PDF)

\section{AUTHOR INFORMATION}

\section{Corresponding Authors}

Amany A. Aboulrous - Production Department, Egyptian

Petroleum Research Institute, Cairo 11727, Egypt;

(1) orcid.org/0000-0002-0727-1087;

Email: amany.a.aboulrous@gmail.com

Amin Sharifi Haddad - School of Engineering, Kings College, University of Aberdeen, Aberdeen AB24 3UE, U.K.;

Email: amin.sharifi@abdn.ac.uk

\section{Authors}

Ahmad Mohamed Alsabagh - Petroleum Application Department, Egyptian Petroleum Research Institute, Cairo 11727, Egypt

Mohamed Mahmoud Abdelhamid - Production Department, Egyptian Petroleum Research Institute, Cairo 11727, Egypt

Tahany Mahmoud - Petroleum Application Department, Egyptian Petroleum Research Institute, Cairo 11727, Egypt

Roozbeh Rafati - School of Engineering, Kings College, University of Aberdeen, Aberdeen AB24 3UE, U.K.

Complete contact information is available at:

https://pubs.acs.org/10.1021/acsomega.1c01373

\section{Author Contributions}

A.M.A., A.A.A., M.M.A., A.S.H., and R.R.: conceptualization, methodology, and writing-review and editing. A.A.A. and M.M.A.: experimental investigation. A.M.A., A.S.H., R.R., A.A.A., and T.M.: validation.

Notes

The authors declare no competing financial interest.

\section{ACKNOWLEDGMENTS}

The Egyptian authors were supported by the Science, Technology \& Innovation Funding Authority (STDF) under grant 30894. The authors from the UK would like to acknowledge the financial support from an Institutional Links grant, ID 352343681, under the Newton-Mosharafa Fund partnership. The grant is funded by the UK Department for Business, Energy and Industrial Strategy and delivered by the British Council. The authors would like to thank the EPRIEOR unit and staff as the surface and interfacial tension and contact angle measurements and chemical flooding tests were conducted at the EPRI-EOR unit.

\section{REFERENCES}

(1) Almalik, M. S.; Attia, A. M.; Jang, L. K. Effects of alkaline flooding on the recovery of Safaniya crude oil of Saudi Arabia. J. Pet. Sci. Eng. 1997, 17, 367-372.

(2) Ayirala, S. C.; Rao, D. N. Multiphase flow and wettability effects of surfactants in porous media. Colloids Surf., A 2004, 241, 313-322.

(3) Ayirala, S. C. Surfactant-induced relative permeability modifications for oil recovery enhancement. MSc Thesis, Graduate Faculty of the Louisiana State University and Agricultural and
Mechanical College, Department of Petroleum Engineering, Baton Rouge, Louisiana, 2002.

(4) Borwankar, R. P.; Wasan, D. T. Dynamic interfacial tensions in acidic crude oil/caustic systems. Part II: Role of dynamic effects in alkaline flooding for enhanced oil recovery. AIChE J. 1986, 32, 467476.

(5) Burk, J. H. Comparison of sodium carbonate, sodium hydroxide, and sodium orthosilicate for EOR. SPE Reservoir Eng. 1987, 2, 9-16.

(6) Curbelo, F. D. S.; Santanna, V. C.; Neto, E. L. B.; Dutra, T. V., Jr.; Dantas, T. N. C.; Neto, A. A. D.; Garnica, A. I. C. Adsorption of nonionic surfactants in sandstones. Colloids Surf., A 2007, 293, 1-4.

(7) ClearTech. Industrial Chemicals, North Corman Industrial Park, Saskatoon S7L 5Z3, Canada. 2006, available from http://www. cleartech.ca/products.html (accessed on January 3, 2021).

(8) Elkamel, A.; Al-Sahhaf, T.; Suttar Ahmed, A. Studying the interactions between an Arabian heavy crude oil and alkaline solutions. J. Pet. Sci. Technol. 2002, 20, 789-807.

(9) Haynes, H. J.; Thrasher, L. W.; Katz, M. L.; Eck, T. R. Enhanced Oil Recovery: An Analysis of the Potential for Enhanced Oil Recovery from Known Fields in the United States; National Petroleum Council: Washington, DC, 1976.

(10) Islam, M. R. New scaling criteria for chemical flooding experiments. J. Can. Pet. Technol. 1990, 29, 30-36.

(11) Islam, M. R. Emerging technologies in enhanced oil recovery. Energy Sources 1999, 21, 97-111.

(12) Islam, M. R.; Farouq Ali, S. M. Numerical simulation of alkaline cosurfactant/polymer flooding. Proceedings of the UNI-TAR/ UNDP Fourth International Conference, Heavy Crude and Tar Sand, Edmonton, Alberta, Canada, 1989. August 7-22, 1988.

(13) Khan, M. I.; Islam, M. R. Handbook of Sustainable Oil and Gas Operations Management; Gulf Publishing Company Houston: Texas. 2008.

(14) Da Cruz, A.; Sanches, R.; Miranda, C.; Brochsztain, S. Evaluation of Cyclodextrins as Environmentally Friendly Wettability Modifiers for Enhanced Oil Recovery. Colloids Interfaces 2018, 2, 10.

(15) Liu, Q.; Dong, M.; Ma, S.; Tu, Y. Surfactant enhanced alkaline flooding for Western Canadian heavy oil recovery. Colloids Surf., A 2007, 293, 63-71.

(16) Liu, Q.; Dong, M.; Yue, X.; Hou, J. Synergy of alkali and surfactant in emulsification of heavy oil in brine. Colloids Surf., A 2006, 273, 219-228.

(17) Mayer, E. H.; Berg, R. L.; Carmichael, J. D.; Weinbrandt, R. M. Alkaline injection for enhanced oil recovery-A status report. J. Pet. Technol. 1983, 35, 209-221.

(18) Chen, H.; Han, L.; Luo, P.; Ye, Z. The interfacial tension between oil and Gemini surfactant solution. Surf. Sci. 2004, 552, L53-L57.

(19) Babu, K.; Pal, N.; Bera, A.; Saxena, V. K.; Mandal, A. Studies on interfacial tension and contact angle of synthesized surfactant and polymeric from castor oil for enhanced oil recovery. Appl. Surf. Sci. 2015, 353, 1126-1136.

(20) Kumar, S.; Saxena, N.; Mandal, A. Synthesis and evaluation of physicochemical properties of anionic polymeric surfactant derived from Jatropha oil for application in enhanced oil recovery. J. Ind. Eng. Chem. 2016, 43, 106-116.

(21) Kumar, A.; Mandal, A. Synthesis and physicochemical characterization of zwitterionic surfactant for application in enhanced oil recovery. J. Mol. Liq. 2017, 243, 61-71.

(22) Yuan, C.; Xu, Z.; Fan, M.; Liu, H.; Xie, Y.; Zhu, T. Study on characteristics and harm of surfactants. J. Chem. Pharm. Res. 2014, 6, 2233-2237.

(23) Stepanets, O. V.; Solov'eva, G. Y.; Mikhailova, A. M.; Kulapin, A. I. Rapid determination of anionic surfactants in seawater under shipboard conditions. J. Anal. Chem. 2001, 56, 290-293.

(24) Lewis, M. A. Chronic toxicities of surfactants and detergent builders to algae: a review and risk assessment. Ecotoxicol. Environ. Saf. 1990, 20, 123-140.

(25) Holmberg, K.; Bo, J.; Kronberg, B. Surfactants and Polymers in Aqueous Solution; Wiley, 2002. 
(26) Kamal, M. S.; Shakil Hussain, S. M.; Fogang, L. T. A Zwitterionic Surfactant Bearing Unsaturated Tail For Enhanced Oil Recovery In High-Temperature High-Salinity Reservoirs. J. Surfactants Deterg. 2018, 21, 165-174.

(27) Moritis, G. EOR continues to unlock oil reserves. Oil Gas J. 2004, 102, 45-49.

(28) Rahman, M. S. Natural materials for EOR and environmental applications. MA.Sc. Thesis, Faculty of Engineering, Dalhousie University, Halifax, Nova Scotia, Canada, 2007.

(29) Kronberg, B.; Holmberg, K.; Lindman, B. Surface Chemistry of Surfactants and Polymers; Wiley: Hoboken, 2014.

(30) Bera, A.; Belhaj, H. Ionic Liquids As Alternatives Of Surfactants In Enhanced Oil Recovery-A State-Of-The-Art Review. J. Mol. Liq. 2016, 224, 177-188.

(31) Sheng, J. Modern Chemical Enhanced Oil Recovery: Theory And Practice; Gulf Professional Publishing: Houston, 2011.

(32) Austad, T.; Hodne, H.; Strand, S.; Veggeland, K. Chemical Flooding Of Oil Reservoirs 5. The Multiphase Behavior Of Oil/ Brine/Surfactant Systems In Relation To Changes In Pressure, Temperature, And Oil Composition. Colloids Surf., A 1996, 108, 253-262.

(33) Wu, Y.; Shuler, P.; Blanco, M.; Tang, Y.; Goddard, W. A. A Study Of Branched Alcohol Propoxylate Sulfate Surfactants For Improved Oil Recovery. SPE Paper 95404, SPE Annual Technical Conference and Exhibition, Dallas, Texas, October 9-12, 2005.

(34) Leng, L.; Chen, J.; Leng, S.; Li, W.; Huajun, H.; Li, H.; Yuan, X.; Li, J.; Zhou, W. Surfactant Assisted Upgrading Fuel Properties Of Waste Cooking Oil Biodiesel. J. Cleaner Prod. 2019, 210, 1376-1384.

(35) Abdel Hameed, R. S. Recycling of the Waste Cooking Oils as Nonionic Surfactants. Mater. Sci.: Indian J. 2016, 15, 104.

(36) Satyarthi, J. K.; Srinivas, D.; Ratnasamy, P. Hydrolysis Of Vegetable Oils And Fats To Fatty Acids Over Solid Acid Catalysts. Appl. Catal., A 2011, 391, 427-435.

(37) Wrigley, A. N.; Smith, F. D.; Stirton, A. J. Synthetic Detergents From Animal Fats VIII. The Ethoxylation Of Fatty Acids And Alcohols. J. Am. Oil Chem. Soc. 1957, 34, 39-43.

(38) Alsabagh, A. M.; Hassan, M. E.; Dosouky, S. D. M.; Nasser, N. M.; Elsharaky, E. A.; Abdelhamid, M. M. Preparation Of Some Thermal Stable Polymers Based On Diesters Of Polyethylene And Polypropylene Oxides Macro Monomers To Use As Surfactants At High Temperature And Pressure, Egypt. J. Pet. 2016, 25, 355-366.

(39) Samak, N. A.; Mahmoud, T.; Aboulrous, A. A.; Abdelhamid, M. M.; Xing, J. Enhanced Biosurfactant Production Using Developed Fed-Batch Fermentation for Effective Heavy Crude Oil Recovery. Energy Fuels 2020, 34, 14560-14572.

(40) Guo, B. Petroleum reservoir properties, Well Productivity Handbook. 2nd ed.; Gulf Professional Publishing, 2019; Chapter 2. pp 17-51

(41) Schrader, M. E. Young-Dupre Revisited. Langmair 1995, 11, 3585-3589.

(42) Dahami, M. A.; Constant, W. D.; Wolcott, J. M. AlcoholAssisted Alkaline Flooding For Enhanced Oil Recovery. Fuel 1988, 67, 1242-1248.

(43) Al-Sabagh, A. M.; Zakaa, M. M.; Noor El-Din, M. R. The Interfacial Tension and Alkane Carbon Number $\left(\mathrm{n}_{\min }\right)$ of Alkyl Benzene Sulfonates in Relation to Enhanced Oil Recovery. Part I: Effect of Surfactant Molecular Weight/Temperature and Electrolyte on $\mathrm{n}_{\min }$. J. Dispersion Sci. Technol. 2009, 30, 1237-1246.

(44) Chen, Z.; Zhao, X. Enhancing Heavy-Oil Recovery by Using Middle Carbon Alcohol-Enhanced Waterflooding, Surfactant Flooding, and Foam Flooding. Energy Fuels 2015, 29, 2153.

(45) Al-Sabagh, A. M.; Zakaa, M. M. Effect of Anionic/Nonionic Surfactants Mixture Systems on Shift The Alkane Carbon Number Using The Interfacial Tension Measurements. J. Dispersion Sci. Technol. 2009, 30, 9-23.

(46) Cayias, J. L.; Schechter, R. S.; Wade, W. H. Modeling crude oils for low interfacial tension. Soc. Pet. Eng. J. 1976, 16, 351-357.
(47) Taylor, K. C.; Hawkins, B. F.; Islam, M. R. Dynamic interfacial tension in surfactant enhanced alkaline flooding. J. Can. Pet. Technol. 1990, 29, 50-54.

(48) Jennings, H. Y.; Newman, G. H. The effect of temperature and pressure on the Interfacial tension of water against Methane normal decane mixtures. Soc. Pet. Eng. J. 1971, 11, 1771-2175.

(49) Sagir, M.; Tan, I. M.; Mushtaq, M.; Ismail, L.; Nadeem, M.; Azam, M. R.; Hashmet, M. R. Novel Surfactant for the Reduction of CO2/Brine Interfacial Tension. J. Dispersion Sci. Technol. 2014, 35, $463-470$. 